\title{
Energy efficiency in China: optimization and comparison between hydropower and thermal power
}

\author{
Ruo-Mei Wang ${ }^{1}$, Ze $\operatorname{Tian}^{2}$ and Fang-rong Ren ${ }^{1 *}$ (])
}

\begin{abstract}
Background: The energy generation efficiencies of thermal power and hydropower, which are the two main forces of electric power in China, are important factors affecting the energy conservation, emission reduction, and green development of the country's whole power industry.

Methods: Considering regional differences and multiple efficient decision-making units (DMUs), this research uses the meta-Frontier super-efficiency slack-based measure (meta-SE-SBM) undesirable model to comprehensively evaluate the efficiencies of hydropower and thermal power generation in China. The $\mathrm{CO}_{2}$ emissions of thermal power generation are taken as the undesirable output.

Results: The ranking of the average meta-efficiency of thermal power generation in China is Eastern China > Central China $>$ Western China, and all regions show an upward trend. However, the ranking of the average meta-efficiency of hydropower generation is Western China > Central China > Eastern China, and all these regions present a downward trend. In 2017, the technology gap ratio (TGR) values for the thermal power generation efficiency of the eastern and western regions showed a rising trend, while that for the central region showed a declining trend. The TGR values of the hydropower generation efficiency of the western region continued to increase, while those of the central and eastern regions decreased. The development trends of the TGR values of the thermal power or hydropower generation efficiencies of the three regions were not consistent with each other, indicating that technological convergence has not been achieved. In the three regions, the technology gaps in hydropower have slightly expanded, but the technology gaps in thermal power have gradually narrowed. The undesirable output $\mathrm{CO}_{2}$ of the thermal power energy efficiency of the three regions is in a surplus, and the generation of hydropower in the eastern and central regions is insufficient.
\end{abstract}

Conclusions: The government and power industry managers should fully consider regional heterogeneity in the efficiency of hydropower and thermal power to reduce the technology gap in China. The thermal power industry is relatively mature, but its $\mathrm{CO}_{2}$ emissions should be controlled. The hydropower industry needs further policy support to promote an efficiency improvement in it under the condition of resource endowments.

Keywords: Energy efficiency, Hydropower, Thermal power, $\mathrm{CO}_{2}$, Super-efficiency slack-based measure model, MetaFrontier

*Correspondence: 180213120008@hhu.edu.cn

${ }^{1}$ Business School, Hohai University, Focheng West Road No. 8, Nanjing 211100, China

Full list of author information is available at the end of the article

\section{Background}

According to the "BP Statistical Review of World Energy 2020 " report [1], coal was still the single largest source of power generation in 2019. In addition, China's power original author(s) and the source, provide a link to the Creative Commons licence, and indicate if changes were made. The images or other third party material in this article are included in the article's Creative Commons licence, unless indicated otherwise in a credit line to the material. If material is not included in the article's Creative Commons licence and your intended use is not permitted by statutory regulation or exceeds the permitted use, you will need to obtain permission directly from the copyright holder. To view a copy of this licence, visit http://creativecommons.org/licenses/by/4.0/. The Creative Commons Public Domain Dedication waiver (http://creativeco mmons.org/publicdomain/zero/1.0/) applies to the data made available in this article, unless otherwise stated in a credit line to the data. 
generation increased $4.7 \%$, accounting for $27.8 \%$ of the world's total amount of power generation, meaning that China's electricity production clearly represents an important share globally. Furthermore, thermal power is currently a major part of China's electricity generation, and coal-fired power generation accounts for most of the nation's thermal power generation. However, rapid fossil fuel consumption has not only caused a global energy crisis but also aggravated eco-environmental problems [2]. To solve these problems, many countries have increased their installed capacity of renewable energy [3]. By the end of 2030, nearly $35 \%$ of the global energy supply will come from renewable energy [4]. As a primary source of renewable energy, hydropower is critically important for ensuring energy supply and carbon emission reduction [5]. Therefore, when targeting the green development of the power industry, the positive role of hydropower cannot be ignored.

Although hydropower has received much attention, its proportion of power generation is still smaller than that of thermal power in China. Data from the 2020 China Electric Power Yearbook [6] show that China's thermal power generation and hydropower generation accounted for $68.9 \%$ and $17.8 \%$ of total power generation, respectively. Under China's current circumstances, in which thermal power is still dominant and hydropower is growing, the following question arises: How can rapidly growing power demand be met and carbon emissions be reduced? In the path to doing so, improving efficiency is the key. Hence, information on the segmentation and effectiveness of China's power generation is urgently needed. Whether for thermal power or hydropower, efficiency assessment is the basis for understanding the pathway toward improvement.

Data envelopment analysis (DEA) models [7-10] have been proposed and used for efficiency evaluation in various fields. In particular, many scholars have used DEA models to conduct energy efficiency assessments [11, 12]. However, the target of such research is energy efficiency, which is relatively extensive. It is necessary to focus on the efficiencies of traditional energy and renewable energy. One of the innovations of this research is that we estimate and compare the generation efficiencies of thermal power and hydropower in China, which can help evaluate and improve the current domestic situation of traditional energy and renewable energy.

Shrivastava et al. [13] and Moon et al. [14] examine the generation efficiency of thermal power plants or companies, while Choi et al. [15], Bi et al. [16], and Song et al. [17] examine the regional thermal power industry. Most scholars take the DEA model to measure thermal power generation efficiency. However, the heterogeneity of production technology in China's provinces (municipalities and autonomous regions) has not been taken into account, even as many scholars prove that meta-Frontier methods can be effective in assessing efficiency under heterogeneous technologies [15-20]. In practice, the technological Frontiers of China's provinces are not the same due to their different geographical locations, regional policies or socioeconomic conditions. Another innovation of this paper is that when measuring the generation efficiencies of the thermal power and hydropower of China's provinces, regional heterogeneity is considered.

Furthermore, many studies have not considered the identification and rankings of efficient decision-making units (DMUs), and any quantitative analysis on this basis may not be accurate. To overcome this limitation, Li and Shi [21] propose the super slack-based measure (superSBM) model to reasonably distinguish between multiple efficient DMUs. The third innovation of our study is that when evaluating the thermal power and hydropower generation efficiencies of China's provinces, the rankings of multiple efficient provinces are distinguished.

As a renewable energy source, hydropower can contribute to reducing carbon emissions [22]. In contrast to hydropower, thermal power causes carbon emissions. To more comprehensively and accurately investigate and compare the efficiency of the two, it is necessary to consider the undesired output of thermal power. The fourth innovation of this article is that when evaluating the generation efficiency of thermal power, we take the $\mathrm{CO}_{2}$ it produces as an undesired output indicator.

Improving thermal power sector efficiency is the best alternative for achieving emission abatement before any advanced technological breakthroughs can be made [23-25]. The lack of systematic methods of evaluating hydropower operational efficiency leads to wasted electric energy [26]. Thus, there is an urgent need to more accurately evaluate the generation efficiency of thermal power and hydropower to enhance the overall efficiency of the power industry.

Our study applies the meta-Frontier super-efficiency slack-based measure (meta-SE-SBM) undesirable model to evaluate the thermal power or hydropower generation efficiency of the eastern, central and western regions of China under the same common benchmark. In addition, it ranks multiple efficient provinces and incorporates undesirable outputs into the measurement system. Specifically, we first measure the average meta-efficiency and group efficiency values of thermal power and hydropower generation in the Eastern, Central, and Western China. Second, we calculate the technology gap ratio (TGR) values of the thermal power and hydropower generation efficiency of the three regions. Third, we give the input-output nonefficiency levels of thermal power and 
hydropower generation. Finally, policy recommendations are offered to promote the green development of the power industry.

The remainder of this paper is organized as follows. "Literature review" conducts a literature review. "Methodology" presents the methodology of this research. "Results and discussion" presents the empirical results and discussion. "Conclusions and policy recommendations" offers conclusions and policy recommendations.

\section{Literature review}

According to the literature review, studies on energy and related eco-environmental efficiency mainly focus on the following three aspects (Table 1 ).

The first aspect covers the influencing factors of energy consumption. Most studies use national or regional data to analyze energy consumption or related $\mathrm{CO}_{2}$ emissions with the help of the logarithmic mean Divisia index (LMDI) method [27-29] and econometric models [30, 31]. These studies indicate that the technology level and energy efficiency play important roles in reducing energy consumption and carbon emissions. However, to formulate energy conservation and emission reduction measures based on local conditions, an accurate discussion of the difference in the energy efficiency and technology level of regions is lacking.

The second aspect concerns the measurement and evaluation of energy efficiency and related eco-environmental efficiency. In the literature on efficiency measurement evaluation, one of the most commonly used methods is DEA, in regard to which there are three main directions: eco-environmental efficiency measurement $[19,32-35]$, energy efficiency at the level of power plants, companies, or firms [13, 14], and regional energy efficiency $[15-17,36]$. Studies evaluate the energy efficiency of thermal power generation and provide research experience for the efficiency assessment of China's power generation. However, when evaluating efficiency, they do not take into account regional heterogeneity. Thus, there is room for further discussion on the efficiency assessment of power generation in China by considering regional heterogeneity and undesired output.

The third aspect is in regard to the measurement and evaluation of renewable energy efficiency and discussion of the relationship between traditional energy and renewable energy. In recent years, increasing attention has been paid to the energy efficiency of hydropower [4, 5]. Studies [37, 38] show that hydropower stations have improved in their technical efficiency, but evaluation and analysis of the efficiency of regional hydropower generation in China are lacking. Furthermore, the relationship between renewable energy and traditional energy [39, $40]$ is receiving increasing attention. As hydropower and thermal power constitute the two pillars of China's power industry, it is necessary to grasp their current efficiency information to better protect the domestic power supply. In summary, the literature provides useful information to conduct accurate measurements and analyses of the regional efficiencies of China's hydropower and thermal power industries.

Acknowledging the existing literature, we find that there still exist some questions to be solved. (1) Most articles concentrate on energy efficiency or eco-environmental efficiency, while few articles are related to power efficiency. However, each industry has different possibilities for improving its own energy efficiency [14, 32]. Furthermore, China's power industry plays an important role globally [1], and thermal power and hydropower are the two main components of China's power industry [39]. Therefore, it is necessary to conduct a more macrolevel efficiency assessment of regional thermal power and hydropower in China, and a comparative analysis of the two still needs to be conducted.

(2) The slack-based measure (SBM) [16], undesirablesuper slack-based measure (US-SBM) [34, 35], metaFrontier [20, 33], super-SBM [21], and meta-Frontier SBM [19] methods have been applied in energy efficiency studies. However, a combined and more accurate measurement that considers regional heterogeneity [18-20, 35], multiple efficient DMU rankings [21], and more comprehensive input-output indicators, especially in the context of the mature development of thermal power and the rise of hydropower, is lacking. Thus, we evaluate meta-efficiency, group efficiency, and TGR values based on the meta-SE-SBM undesirable model, which contributes to conducting an objective and accurate efficiency assessment of the hydropower and thermal power generation of different regions in China.

\section{Methodology \\ SE-SBM model}

DEA has been widely used in the field of energy efficiency [41], because it has no specification for the functional form of the production relationship and has the advantages of avoiding subjective factors and reducing errors. Taking into account the differences in the multiple input and output variables of thermal power and hydropower, the SBM model can be selected [10], because it considers slack improvement. As limitations, however, it is impossible for the SBM model to effectively identify and compare efficient DMUs, and quantitative comparison and analysis on this basis may not be accurate. The development of China's thermal power industry is relatively mature [39], and there may be multiple efficient provinces. The western region is rich in hydropower resources, and there may also be multiple efficient provinces. Thus, the 


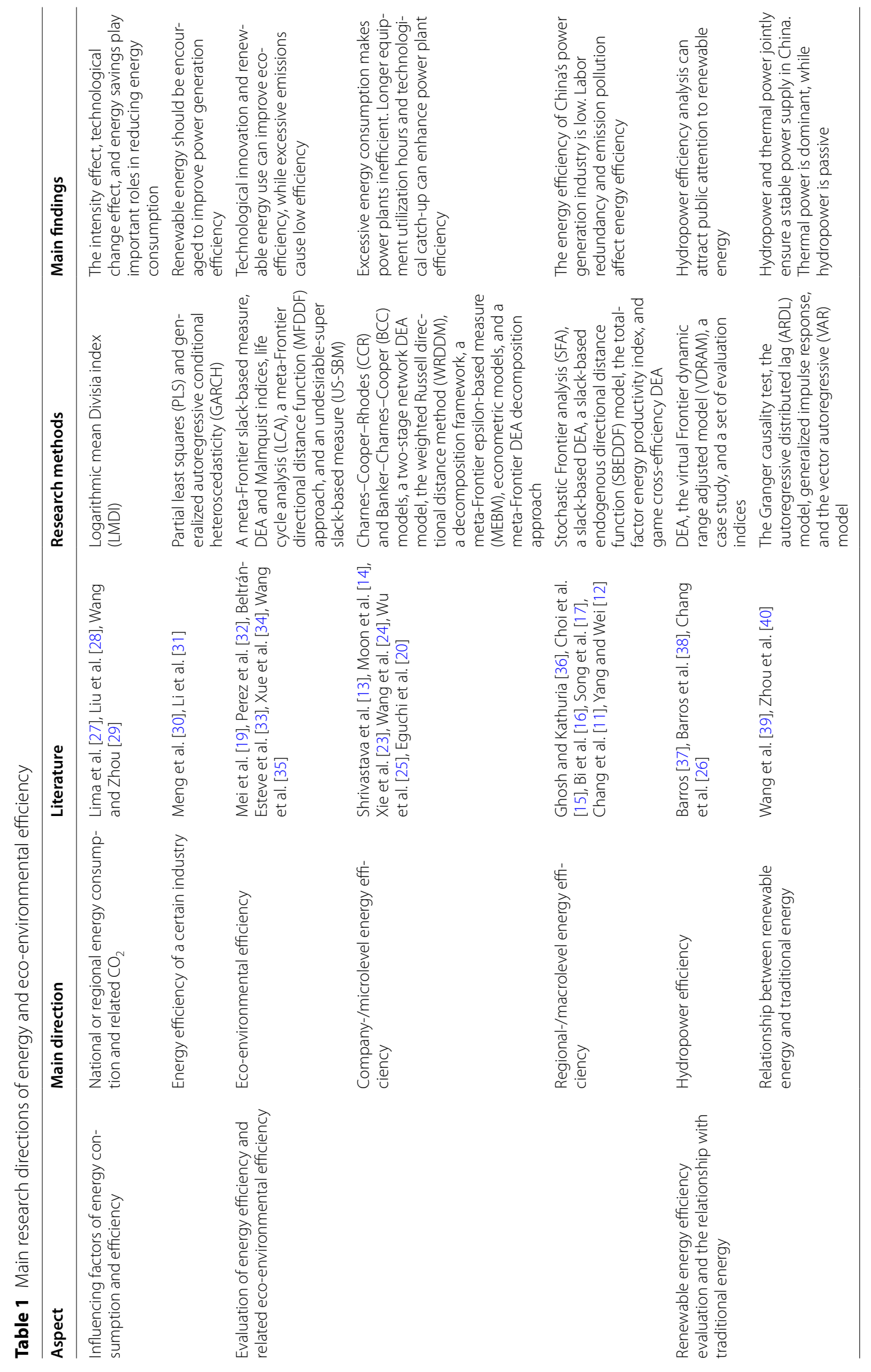


super-efficiency slack-based measure (SE-SBM) model has been proposed to solve the problem of differentiating the efficiency of DMUs and, simultaneously, incorporating undesirable outputs into the measurement system $[21,42]$, as it can more realistically and comprehensively reflect regional power efficiency. It can accurately assess the efficiencies of the thermal power and hydropower of different provinces in China and identify efficient provinces:

$$
\min \rho=\frac{1+\frac{1}{\mathrm{~m}} \sum_{\mathrm{i}=1}^{\mathrm{m}} \frac{\mathrm{s}_{\mathrm{i}}^{-}}{\mathrm{x}_{\mathrm{ik}}}}{1-\frac{1}{\mathrm{q}_{1}+\mathrm{q}_{2}}\left(\sum_{\mathrm{r}=1}^{\mathrm{q}_{1}} \frac{\mathrm{s}_{\mathrm{r}}^{\mathrm{g}^{+}}}{\mathrm{y}_{\mathrm{rk}}^{\mathrm{g}}}+\sum_{\mathrm{r}=1}^{\mathrm{q}_{2}} \frac{\mathrm{s}_{\mathrm{t}}^{\mathrm{b}^{-}}}{\mathrm{y}_{\mathrm{rk}}^{\mathrm{b}}}\right)}
$$

evaluate regional thermal power and hydropower efficiency in China. With respect to regional heterogeneity, O'Donnell et al. [43] established a meta-Frontier framework based on DEA that can accurately calculate the group and meta-Frontier technical efficiencies.

Suppose that all DMUs are divided into $H$ groups and that DMUs are grouped based on the division of China's eastern, central, and western regions. Group-Frontier efficiency is calculated using the SE-SBM model to measure the efficiency of DMUs in the same group under the group boundary. Meta-Frontier efficiency is calculated using the SE-SBM model to measure the efficiency of DMUs in the total group under the same boundary. Since the meta-Frontier contains the group Frontier of

$$
\begin{aligned}
& \text { s.t. } \sum_{j=1, j \neq k}^{n} x_{i j} \lambda_{j}-s_{i}^{-} \leq x_{i k}, \sum_{j=1, j \neq k}^{n} y_{r j} \lambda_{j}+s_{r}^{g^{+}} \geq y_{r k}^{g}, \sum_{j=1, j \neq k}^{n} y_{t j}^{b}-s_{t}^{b^{-}} \leq y_{t k}^{b} \\
& 1-\frac{1}{q_{1}+q_{2}}\left(\sum_{r=1}^{q_{1}} \frac{s_{r}^{g}}{y_{r k}^{g}}+\sum_{r=1}^{q^{2}} \frac{s_{r}^{b}}{y_{r k}^{b}}\right)>0, s^{-}>0, s^{b}>0, s^{g}>0, \lambda>0
\end{aligned}
$$

$$
i=1,2, \ldots m ; r=1,2, \ldots q ; j=1,2, \ldots n(j \neq k)
$$

The SE-SBM model (Eq. 1) assumes that there are $n$ DMUs and that each DMU has $m$ inputs $(x), s_{1}$ desirable output $\left(y^{g}\right)$, and $s_{2}$ undesirable output $\left(y^{b}\right)$. We define matrices $X, Y^{g}$, and $Y^{b}$ as $X=\left[x_{1}, x_{2}, \ldots x_{n}\right]$, $Y^{g}=\left[y_{1}^{g}, y_{2}^{g}, \ldots y_{n}^{g}\right]$, and $Y^{b}=\left[y_{1}^{b}, y_{2}^{b}, \ldots y_{n}^{b}\right]$, respectively. In addition, $s$ is the amount of slack in the input and output, $\lambda$ is the weight vector, and the objective function is $\rho$, whose value is between 0 and 1 . Here, $x_{i j}$ is the $i$ th input of the $j$ th DMU, and $y_{r j}$ is the $r$ th output of the $j$ th DMU.

\section{Meta-Frontier and the technology gap ratio}

Traditional DEA generally assumes that all producers have the same level of technology, but the assessed DMUs are often in different geographical locations or under different national policies or socioeconomic conditions [19]. The technological Frontiers of these DMUs are not the same; that is, there are heterogeneous technologies. If the homogeneity assumption is adopted without considering the difference in technological Frontiers, then the efficiency measurement results may be biased.

However, many existing studies on power efficiency do not take into account regional heterogeneity [13, 15-17]. In practice, in the different provinces of China, there are differences in economic and social development, regional policies, resource endowments, etc. Thus, taking into account the heterogeneity of different regions can help
$H$ groups, the technical efficiency of the meta-Frontier (MFE) is less than the technical efficiency of the group Frontier (GFE). The calculated value is called the technical efficiency gap ratio (or the TGR). The formula is as follows:

$$
\mathrm{TGR}=\frac{\rho *}{\rho_{0}^{* H}}=\frac{\mathrm{MFE}}{\mathrm{GFE}}
$$

In Eq. (2), the larger the TGR is, the closer the production technology used by the DMU is to the Frontier of production technology.

\section{Meta-SE-SBM undesirable model}

To fully consider regional heterogeneity, identify multiple efficient provinces, incorporate undesired output $\mathrm{CO}_{2}$ of thermal power, and combine the meta-Frontier method and super-SBM model, we apply the meta-SE-SBM undesirable model to evaluate the regional efficiency of thermal power and hydropower in China. This model is similar to the SE-SBM model proposed by Huang [44]. Assume that the number of DMUs is $N$ and that they are divided into $H$ groups $(H>1)$ based on some heterogeneous characteristics. In this paper, the three $H$ groups are China's eastern, central, and western regions.

We define the number of DMUs in the $H$ groups as $N_{h}$, and then, $\sum_{h=1}^{H} N_{h}=N$. Assume that each DMU has three types of input and output variables, i.e., inputs, desirable outputs, and 
undesirable outputs, which are expressed as $x=\left[x_{1}, x_{2}, \ldots, x_{M}\right] \in R_{+}^{M}, \quad y=\left[y_{1}, y_{2}, \ldots, y_{R}\right] \in R_{+}^{R}$, and $b=\left[b_{1}, b_{2}, \cdots, b_{J}\right] \in R_{+}^{J}$, respectively. In turn, $M$, $R$, and $J$ represent the number of the three types of variables. When considering both undesirable output and heterogeneous technologies, the efficiency of the $k$ th group of the $o$ th DMU $\left(o=1,2, \ldots, N_{k} ; k=1,2, \ldots, H\right)$ for the nondirected and nonradial SBM of the meta-Frontier formed by all groups can be obtained by solving the following:

$$
\begin{aligned}
& \rho_{k o}{ }^{\text {Meta } *}=\min \frac{1+\frac{1}{M} \sum_{m=1}^{\mathrm{M}} \frac{\mathrm{s}_{\mathrm{mko}}^{\mathrm{x}}}{\mathrm{x}_{\mathrm{mko}}}}{1-\frac{1}{\mathrm{R}+\mathrm{J}}\left(\sum_{\mathrm{r}=1}^{\mathrm{R}} \frac{\mathrm{s}_{\mathrm{rko}}^{\mathrm{y}}}{\mathrm{y}_{\mathrm{rko}}}+\sum_{\mathrm{j}=1}^{\mathrm{J}} \frac{\mathrm{s}_{\mathrm{jko}}^{\mathrm{b}}}{\mathrm{b}_{\mathrm{jko}}}\right)} \\
& \text { s.t. } x_{\text {mko }}-\sum_{\mathrm{h}=1}^{\mathrm{H}} \sum_{\mathrm{n}=1, \mathrm{n} \neq 0 \text { if } \mathrm{h}=\mathrm{k}}^{\mathrm{N}_{\mathrm{h}}} \xi_{\mathrm{n}}^{\mathrm{h}} \mathrm{x}_{\mathrm{mhn}}+\mathrm{s}_{\mathrm{mko}}^{\mathrm{x}} \geq 0 \\
& \sum_{h=1}^{H} \sum_{n=1, n \neq 0 \text { if } h=k}^{N_{h}} \xi_{n}^{h} y_{r h n}-y_{r k o}+s_{r k o}^{y} \geq 0 \\
& b_{j k o}-\sum_{h=1}^{H} \sum_{n=1, n \neq 0 \text { if } h=k}^{N_{h}} \xi_{n}^{h} b_{j h n}+s_{j k o}^{b} \geq 0 \\
& 1-\frac{1}{R+J}\left(\sum_{r=1}^{R} \frac{s_{r k o}^{y}}{y_{r k o}}+\sum_{j=1}^{J} \frac{s_{j k o}^{b}}{b_{j k o}}\right) \geq \varepsilon \\
& \xi_{n}^{h}, s^{x}, s^{y}, s^{b} \geq 0 \\
& m=1,2, \ldots, M ; r=1,2, \ldots, R ; j=1,2, \ldots, J
\end{aligned}
$$

In Eq. (3), $\mathcal{\xi}$ is a nonnegative weight vector, $\varepsilon$ is nonArchimedean and infinitely small, and $s^{x}, s^{y}$, and $s^{b}$ are slack variables of the input, desirable output, and undesirable output of $\mathrm{DMU}_{\mathrm{ko}}$, respectively. The constraint $1-\frac{1}{R+J}\left(\sum_{r=1}^{R} \frac{s_{r k o}^{y}}{y_{r k o}}+\sum_{j=1}^{J} \frac{s_{j k o}^{b}}{b_{j k o}}\right) \geq \varepsilon$ is added to ensure that the denominator of the objective function is not zero. If variable returns to scale (VRS) are assumed, then the constraint $\sum_{h=1}^{H} \sum_{n=1, n \neq 0}^{N_{h}}$ if $h=k \xi_{n}^{h}=1$ here should be added.

\section{Data sources and description}

Due to a lack of statistical data, this study does not consider Hong Kong, Macau, Taiwan, or Tibet as DMUs. To consider regional differences, following Liu et al. [45], this study divides 30 provinces and cities in China into three major regions. The eastern region includes Beijing, Tianjin, Hebei, Liaoning, Shanghai, Jiangsu, Zhejiang, Fujian, Shandong, Guangdong, and Hainan, for a total of 11 provinces; the central region includes Shanxi, Inner
Mongolia, Jilin, Heilongjiang, Anhui, Jiangxi, Henan, Hubei, Hunan, and Guangxi, for a total of 10 provinces; and the western region includes Chongqing, Sichuan, Guizhou, Yunnan, Shaanxi, Gansu, Qinghai, Ningxia, and Xinjiang, for a total of 9 provinces. This study uses the latest data representing China's provinces to measure thermal power efficiency, and it takes the latest data from 28 provinces (excluding Shanghai and Tianjin) to measure hydropower efficiency. Shanghai's hydropower generation has been zero over the years, while Tianjin's hydropower indicators are lacking. Therefore, when calculating hydropower efficiency, Shanghai and Tianjin are not considered. The data come from the China Statistical Yearbook [46], China Energy Statistical Yearbook [47], and China Electric Power Statistical Yearbook [48], and relevant data for 2013 and 2017 are collected.

In terms of input-output indicators, scholars have used diversified input-output indicators in their energy efficiency calculations, but they have common points, such as [15-17, 30, 49]. The input indicators are mostly labor and capital, but special input indicators of raw materials and equipment are also counted, especially in the power industry. Previous studies have shown that installed capacity and equipment utilization hours significantly affect the energy performance of power stations [16, 25, 56]. Therefore, when evaluating the efficiency of thermal power and hydropower generation, installed capacity and equipment utilization hours are included in the input indicators. In addition, the output indicators typically include the production volume and GDP. Considering that China's thermal power generation mainly relies on coal-fired power plants, which yield a large amount of carbon emissions [2], undesirable output that is unfavorable to the environment must be considered. Most studies, such as [50-54], have selected $\mathrm{CO}_{2}$ emissions to reflect the requirements of the green development of energy and to make efficiency measurements more real and effective.

The input and output variables are selected based on a comprehensive consideration of previous research experience and data availability. Specifically, following Zhou et al. [54] and Qu et al. [55], we select labor, installed capacity, and energy consumption as input indicators, and power generation is taken as the output indicator to measure power efficiency. In addition, $\mathrm{Qu}$ et al. [55] chose undesirable output $\mathrm{CO}_{2}$ emissions, because such emissions are mainly emitted from coalfired thermal power generation. Bi et al. [16], Wu et al. [25], and Saglam [56] also considered installed capacity as one of the most important input indicators because of the strong correlation between installed capacity and generated electricity. Wu et al. [25] further pointed out that equipment utilization hours have an important 
impact on efficiency based on 528 thermal power stations in Northern China. Zhou and Ang [57] and Bi et al. [16] separated inputs into energy inputs and nonenergy inputs, where the former are types of fossil fuel and the latter include capital and labor. Capital is measured in terms of installed thermal generating capacity. Therefore, our input-output indicators are more comprehensive and can fully evaluate the power generation efficiency of thermal power and hydropower in China.

Input indicators: (1) Urban employees in the electricity, gas, and water production and supply industries are the proxy variable for labor input in the hydropower and thermal power industries; the unit is 10,000 people. (2) Installed capacity refers to the sum of the rated active power of generator sets actually installed in the power system. It is used to measure the scale of investment in thermal power or hydropower generation equipment in each province; the unit is 10,000 kilowatts $(\mathrm{kW})$. (3) Hours are used to indicate the effective utilization rate of equipment, which clearly reflects the situation of installed power generation capacity and whether there is any excess; the unit is h. (4) Energy is an important input for the operation of thermal power generation. The energy-related input of thermal power generation mainly includes coal, oil, and natural gas. The thermal power input data are from the fossil fuel data of the thermal power industry provided by the China Energy Statistics Yearbook [47], and these data mainly include coal, oil, and natural gas; the unit is 10,000 tons of standard coal. The hydropower energy input data are obtained from the China Electric Power Yearbook [48]; its unit is also 10,000 tons of standard coal.

Desirable output indicator: Power generation directly reflects the actual production performance level of the power industry. The amount of power generation is selected as an important indicator to measure its output; the unit is 100 million kilowatt hours (KWh).

Undesirable output indicator: Due to the nature of clean energy, for hydropower, no undesirable output is considered. For energy consumption and carbon emissions, China's thermal power generation industry is an important sector. Therefore, the undesired output of thermal power must be fully considered. In the calculation of thermal power efficiency, $\mathrm{CO}_{2}$ emissions from thermal power generation are selected as the undesirable output, and the unit is 10,000 tons. Based on Liu et al. [58] and Qin et al. [53] as well as provincial-level data on the fossil fuel energy consumption of the thermal power industry, carbon dioxide emissions are estimated based on thermal power generation in China's provinces in 2013 and 2017. The formula is as follows:
Table 2 Kaiser-Meyer-Olkin (KMO) and Bartlett's test

\begin{tabular}{ll}
\hline Thermal power & \\
Kaiser-Meyer-Olkin measure of sampling adequacy & 0.731 \\
Bartlett's test of sphericity & \\
Approx. Chi-square & 681.952 \\
$d f$ & 15 \\
Sig & 0.000 \\
Hydropower & \\
Kaiser-Meyer-Olkin measure of sampling adequacy & 0.777 \\
Bartlett's test of sphericity & \\
Approx. Chi-square & 535.515 \\
df & 10 \\
Sig & 0.000
\end{tabular}

The data are from the authors' collection

Table 3 Communalities of thermal power and hydropower

\begin{tabular}{lll}
\hline Variable & Initial & Extraction \\
\hline Thermal power & & \\
Generation capacity & 1.000 & 0.729 \\
$\mathrm{CO}_{2}$ & 1.000 & 0.945 \\
Hours & 1.000 & 0.870 \\
Labor & 1.000 & 0.708 \\
Energy & 1.000 & 0.947 \\
Installed capacity & 1.000 & 0.939 \\
Hydropower & & \\
Generation capacity & 1.000 & 0.980 \\
Hours & 1.000 & 0.739 \\
Labor & 1.000 & 0.879 \\
Energy & 1.000 & 0.976 \\
Install capacity & 1.000 & 0.983
\end{tabular}

The data are from the authors' collection

$$
\mathrm{C}_{i t}=\sum E_{i j t} \times \mathrm{CEF}_{j} \times \mathrm{COR}_{j} \times \frac{44}{12}
$$

Among the variables above, $\mathrm{C}_{i t}$ is carbon dioxide emissions caused by the energy consumption of thermal power generation in area $i$ in 1 year; $E_{i j t}$ is the $j$-type energy consumption of thermal power generation in area $i$; $\mathrm{CEF}_{j}$ represents the carbon emission factor; $\mathrm{COR}_{j}$ represents the rate of carbon oxidation; and the coefficients of these last two variables are from the research of Liu et al. [58] and Qin et al. [53].

To further verify the acceptability of the input-output indicators, relevant tests involving factor analysis of the indicators selected are added. The results of principal component analysis using IBM SPSS Statistics 20.0 are shown in Tables 2 and 3.

In the principal component analysis of the input and output indicators of thermal power generation 
efficiency, Kaiser-Meyer-Olkin (KMO) value is 0.731, and the approximate Chi-square from Bartlett's test of sphericity is large $(>0.5)$ and significant $(p$ value 0.01 ), indicating that there is a significant correlation between the selected indicators. In the principal component analysis of the input and output indicators of hydropower generation efficiency, the KMO value is 0.777, and the approximate Chi-square from Bartlett's test of sphericity is large $(>0.5)$ and significant $(p$ value 0.01 ), indicating that there is a significant correlation between the selected indicators.

Table 4 Statistical presentation of the input-output variables of thermal power

\begin{tabular}{lrrrr}
\hline Variable & Mean & Std. dev & \multicolumn{1}{l}{ Max } & \multicolumn{1}{c}{ Min } \\
\hline $\begin{array}{l}\text { Descriptive statistical analysis of thermal power } \\
\text { Input }\end{array}$ & & \\
Installed capacity & 3290.42 & 2406.95 & $10,335.00$ & 235.00 \\
Energy & 4660.97 & 3714.04 & $15,427.17$ & 515.66 \\
Hours & 4450.53 & 895.96 & 6173.00 & 1405.00 \\
Labor & 12.99 & 7.04 & 32.18 & 1.85 \\
Output & & & & \\
Generation capacity & 1575.70 & 1395.59 & 7555.00 & 136.00 \\
Undesirable output & & & & \\
CO 2 & $11,424.99$ & 9126.17 & $38,179.86$ & 1212.11 \\
Descriptive statistical analysis of hydropower & & \\
Input & & & & \\
Installed capacity & 1110.40 & 1589.65 & 7714.00 & 43.00 \\
Energy & 1123.53 & 1872.87 & 9236.01 & 12.28 \\
Hours & 2653.93 & 1152.39 & 4599.00 & 355.00 \\
Labor & 13.59 & 6.90 & 32.18 & 1.85 \\
Output & & & & \\
Generation capacity & 371.15 & 634.39 & 3164.00 & 4.50 \\
\hline
\end{tabular}

According to the results of the principal component analysis of the input and output indicators of thermal power generation efficiency, the extraction of the variables is greater than 0.70 . Thus, these variables are suitable for evaluating the generation efficiency of China's thermal power industry. Furthermore, according to the results of the principal component analysis of the input and output indicators of hydropower generation efficiency, the extraction of the variables is once again greater than 0.70 . Thus, these variables are also suitable for evaluating the generation efficiency of China's hydropower industry.

\section{Results and discussion}

\section{Input-output indicator statistics}

Table 4 summarizes the descriptive statistics of the mean, standard deviation, maximum, and minimum of the input variables, desirable output variables, and undesirable output variables used in the model.

Figure 1 illustrates the trend of $\mathrm{CO}_{2}$ emissions from thermal power generation in China's provinces in 2013 and 2017. $\mathrm{CO}_{2}$ emissions are on the rise, and thus, the issue of $\mathrm{CO}_{2}$ from thermal power generation requires improvement. For thermal power generation, the energy efficiency calculation must also consider $\mathrm{CO}_{2}$ emissions to be more realistic.

\section{Meta- and group efficiency scores and rankings of thermal power and hydropower}

This study uses MaxDEA Pro 7.0 software to measure the energy efficiency of thermal power and hydropower in China's provinces and cities in 2013 and 2017, and it selects output-oriented and nonradial types in the efficiency measurement. Among them, in the measurement of thermal power energy efficiency, the ratio of desirable output to undesirable output is set to $1: 1$; that is, $\mathrm{CO}_{2}$

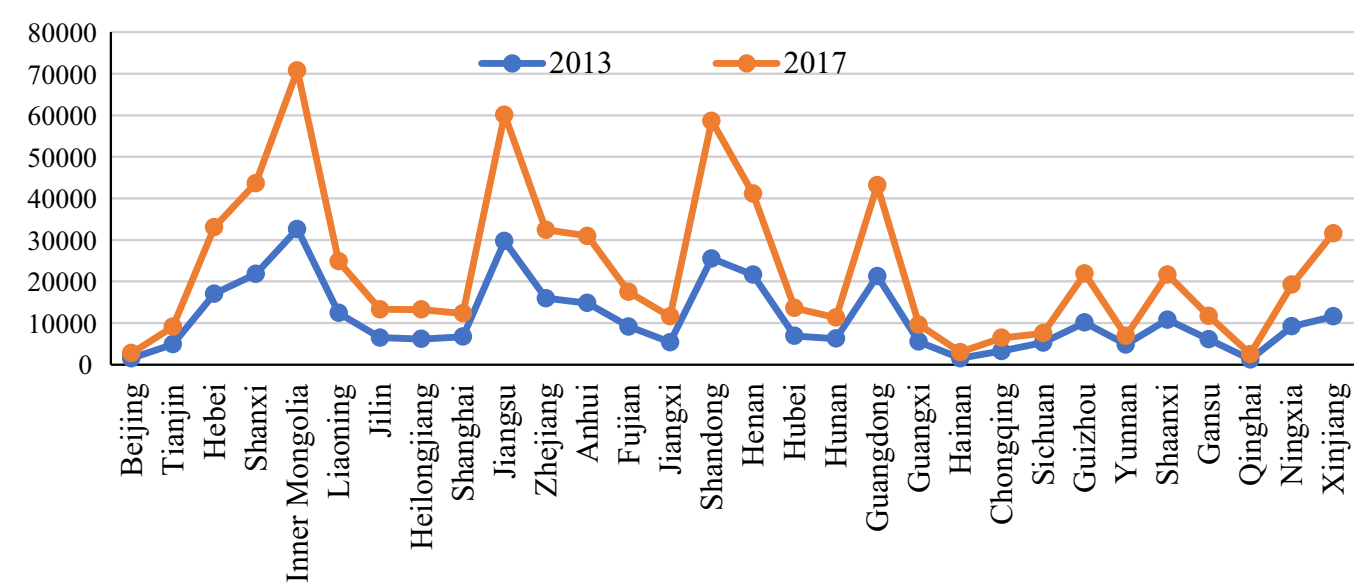

Fig. 1 Regional $\mathrm{CO}_{2}$ emissions in China in 2013 and 2017. The data are from the authors' collection 
emissions and thermal power generation are placed in the same position.

The meta-efficiency scores reflect the thermal power efficiency and hydropower efficiency of China's provinces without considering group differences. According to the calculation results in Table 5, the specific analysis is as follows.

In 2017, the meta-efficiency scores of thermal power in Beijing, Jiangsu, Ningxia, Shandong, Hebei, Jiangxi, Zhejiang, and Inner Mongolia were all higher than 1. This result indicates that the thermal power generation efficiency of these provinces is high. In recent years, China's thermal power industry has been transformed and upgraded, focusing on energy conservation and emission reduction. For example, the rankings of Beijing and Hebei have greatly increased. Compared to 2013, the meta-efficiency score of thermal power in Beijing increased by 19 places in 2017, as its meta-efficiency score rose from 0.2716 to 1.3193 . This increase may be related to the policies adopted by the local government. As policies, Beijing's 2013-2017 Work Plan for Accelerating the Reduction of Coal Combustion and Clean Energy

Table 5 Meta-efficiency scores and thermal power and hydropower rankings in 2013 and 2017

\begin{tabular}{|c|c|c|c|c|c|c|c|c|}
\hline \multirow[t]{3}{*}{ DMU } & \multicolumn{4}{|c|}{ Thermal power } & \multicolumn{4}{|c|}{ Hydropower } \\
\hline & \multicolumn{2}{|l|}{2013} & \multicolumn{2}{|l|}{2017} & \multicolumn{2}{|l|}{2013} & \multicolumn{2}{|l|}{2017} \\
\hline & Rank & Meta score & Rank & Meta score & Rank & Meta score & Rank & Meta score \\
\hline Beijing & 20 & 0.2716 & 1 & 1.3193 & 5 & 1.1656 & 15 & 0.8217 \\
\hline Tianjin & 15 & 0.3604 & 14 & 0.9272 & - & - & - & - \\
\hline Hebei & 14 & 0.3657 & 5 & 1.0226 & 27 & 0.8897 & 27 & 0.5852 \\
\hline Liaoning & 16 & 0.2951 & 25 & 0.8494 & 16 & 0.9743 & 25 & 0.6311 \\
\hline Shanghai & 8 & 0.4447 & 9 & 0.9883 & - & - & - & - \\
\hline Jiangsu & 3 & 0.5064 & 2 & 1.1146 & 23 & 0.9368 & 2 & 1.3506 \\
\hline Zhejiang & 9 & 0.4363 & 7 & 1.0211 & 8 & 1.0164 & 21 & 0.7283 \\
\hline Fujian & 13 & 0.3853 & 16 & 0.9173 & 9 & 1.0111 & 19 & 0.7633 \\
\hline Shandong & 5 & 0.4928 & 4 & 1.0381 & 28 & 0.8475 & 28 & 0.3363 \\
\hline Guangdong & 7 & 0.4673 & 10 & 0.9839 & 11 & 0.9867 & 24 & 0.6594 \\
\hline Hainan & 18 & 0.2824 & 23 & 0.8711 & 7 & 1.0234 & 8 & 0.9874 \\
\hline Eastern group average & 2 & 0.3916 & 1 & 1.0048 & 2 & 0.9835 & 3 & 0.7626 \\
\hline Shanxi & 6 & 0.4840 & 22 & 0.8736 & 22 & 0.9426 & 18 & 0.7830 \\
\hline Inner Mongolia & 4 & 0.5027 & 8 & 1.0055 & 21 & 0.9486 & 26 & 0.6198 \\
\hline Jilin & 28 & 0.1883 & 30 & 0.7584 & 10 & 0.9873 & 20 & 0.7485 \\
\hline Heilongjiang & 26 & 0.2002 & 26 & 0.8346 & 24 & 0.9363 & 16 & 0.8159 \\
\hline Anhui & 12 & 0.4103 & 11 & 0.9719 & 19 & 0.9497 & 22 & 0.7203 \\
\hline Jiangxi & 27 & 0.1917 & 6 & 1.0219 & 14 & 0.9769 & 23 & 0.6871 \\
\hline Henan & 10 & 0.4310 & 15 & 0.9269 & 13 & 0.9833 & 14 & 0.8528 \\
\hline Hubei & 21 & 0.2426 & 12 & 0.9653 & 6 & 1.0403 & 6 & 1.0184 \\
\hline Hunan & 24 & 0.2094 & 13 & 0.9302 & 15 & 0.9758 & 17 & 0.7878 \\
\hline Guangxi & 1 & 1.8055 & 20 & 0.8945 & 12 & 0.9867 & 12 & 0.9139 \\
\hline Central group average & 1 & 0.4666 & 2 & 0.9183 & 3 & 0.9727 & 2 & 0.7947 \\
\hline Chongqing & 25 & 0.2024 & 21 & 0.8771 & 26 & 0.9184 & 13 & 0.9037 \\
\hline Sichuan & 29 & 0.1721 & 18 & 0.8977 & 4 & 1.2139 & 3 & 1.2117 \\
\hline Guizhou & 19 & 0.2824 & 27 & 0.8262 & 17 & 0.9552 & 11 & 0.9192 \\
\hline Yunnan & 30 & 0.1636 & 29 & 0.8037 & 1 & 1.6576 & 1 & 1.6925 \\
\hline Shaanxi & 17 & 0.2896 & 17 & 0.9142 & 20 & 0.9487 & 5 & 1.0476 \\
\hline Gansu & 23 & 0.2293 & 24 & 0.8540 & 3 & 1.2182 & 4 & 1.0781 \\
\hline Qinghai & 22 & 0.2375 & 28 & 0.8192 & 2 & 1.4576 & 9 & 0.9642 \\
\hline Ningxia & 2 & 0.5602 & 3 & 1.0570 & 18 & 0.9530 & 10 & 0.9460 \\
\hline Xinjiang & 11 & 0.4139 & 19 & 0.8973 & 25 & 0.9256 & 7 & 1.0156 \\
\hline Western group average & 3 & 0.2834 & 3 & 0.8829 & 1 & 1.1387 & 1 & 1.0865 \\
\hline Total mean & - & 0.3842 & - & 0.9394 & - & 1.0295 & - & 0.8782 \\
\hline
\end{tabular}


Construction and Hebei's Opinions on Vigorously Promoting the Comprehensive Treatment of Air Pollution have been implemented to strengthen the comprehensive management of coal and to eliminate backward production capacity for the thermal power industry.

Regarding hydropower, the meta-efficiency scores of Yunnan, Jiangsu, Sichuan, Gansu, Shaanxi, Hubei, and Xinjiang are higher than 1 , indicating that the hydropower generation efficiency of these provinces is high. For example, Xinjiang greatly rose in the rankings. Xinjiang's ranking increased by 18 places in 2017, as its metaefficiency score rose from 0.9256 to 1.0156. Yunnan, Sichuan, Gansu, and Xinjiang have rapid water flow and good hydropower resource advantages; thus, their hydropower development is relatively strong.

We further found that in 2017, the hydropower and thermal power meta-efficiency scores of Jiangsu were both higher than 1 . The meta-efficiency score of Jiangsu's hydropower rose 21 places in 2017, as its efficiency score went from 0.9368 to 1.3506 . The hydropower generation efficiency in Jiangsu is relatively high, which is similar to the findings in Tian et al. [59]. However, they focused on hydropower efficiency in the Yangtze River Economic Belt via the traditional CCR model, without considering regional heterogeneity and multiple efficient DMUs, which may not be sufficiently accurate for a rigorous analysis. Therefore, our study on the hydropower efficiency evaluation of different regions in China is warranted.

Interestingly, Jiangxi's thermal power meta-efficiency ranking in 2017 increased by 21 places, as its meta-efficiency score rose from 0.1917 to 1.0219 , while its hydropower generation meta-efficiency ranking has fallen. At present, Jiangxi still maintains a coal-based electricity production pattern. The application of desulfurization and denitration equipment has increased, and the government policy effect of energy savings and environmental protection is more obvious, which has enabled thermal power in Jiangxi to achieve good development. However, its hydropower resource development conditions are poor, which also limits the province's ability to improve its hydropower efficiency. This situation inspires us to take into account local resource endowments and adapt measures to local conditions when formulating policies to promote renewable energy development.

Figure 2 shows the average meta-efficiency scores of hydropower and thermal power generation in the eastern, central, and western regions in 2013 and 2017. Comparing 2013 and 2017, we see that the average metaefficiency scores of thermal power generation in the three regions all show a significant upward trend. However, the average meta-efficiency scores of hydropower generation in the eastern and central regions show a significant

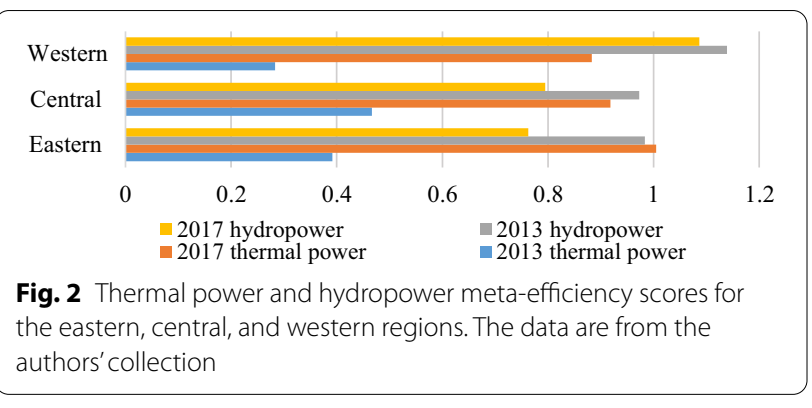

downward trend, while the scores for the western region have a slight downward trend. In terms of thermal power generation, in 2017, the average meta-efficiency ranking was Eastern China > Central China > Western China; the corresponding values are 1.0048, 0.9183, and 0.8829, respectively. In terms of hydropower generation, in 2017, the meta-efficiency ranking of hydropower generation was Western China >Central China $>$ Eastern China; the corresponding values are 1.0865, 0.7947, and 0.7626, respectively. The reasons for this result mainly relate to the economic level [20] and resource endowments of these regions. The eastern region has a better economic foundation and government management, while the central and western areas do not have the same conditions [19]. The eastern region has advanced denitration facilities, a good management level, and more mature market mechanisms, and thus, its thermal power generation efficiency ranks first. Western China's hydropower generation efficiency ranks first due to the region's geographic location and rich hydropower resource advantages.

Figure 3 exhibits a comparison of the group efficiency score and the meta-efficiency score of thermal power generation in China's provinces in 2013 and 2017. Group efficiency reflects the relative efficiency of each province in its group, excluding variations caused by group differences. The specific analysis is as follows. In the eastern region, the group efficiency scores of Beijing, Jiangsu, and Zhejiang are greater than 1 , and in the western region, the group efficiency scores of Chongqing, Shaanxi, Ningxia, and Xinjiang are also greater than 1, indicating that these provinces are at the efficient production Frontier.

Figure 4 shows the comparison results of the group efficiency and meta-efficiency of thermal power generation in the eastern, central, and western regions in 2013 and 2017. The level of generation efficiency measured under one Frontier cannot be compared with that measured under another Frontier because of regionally heterogeneous technologies. It is expected that the meta-efficiency for regions measured under meta-Frontier technology is lower than the group efficiency, which indicates the existence of a technology gap between the meta-Frontier and group Frontiers. The result here is similar to some studies 


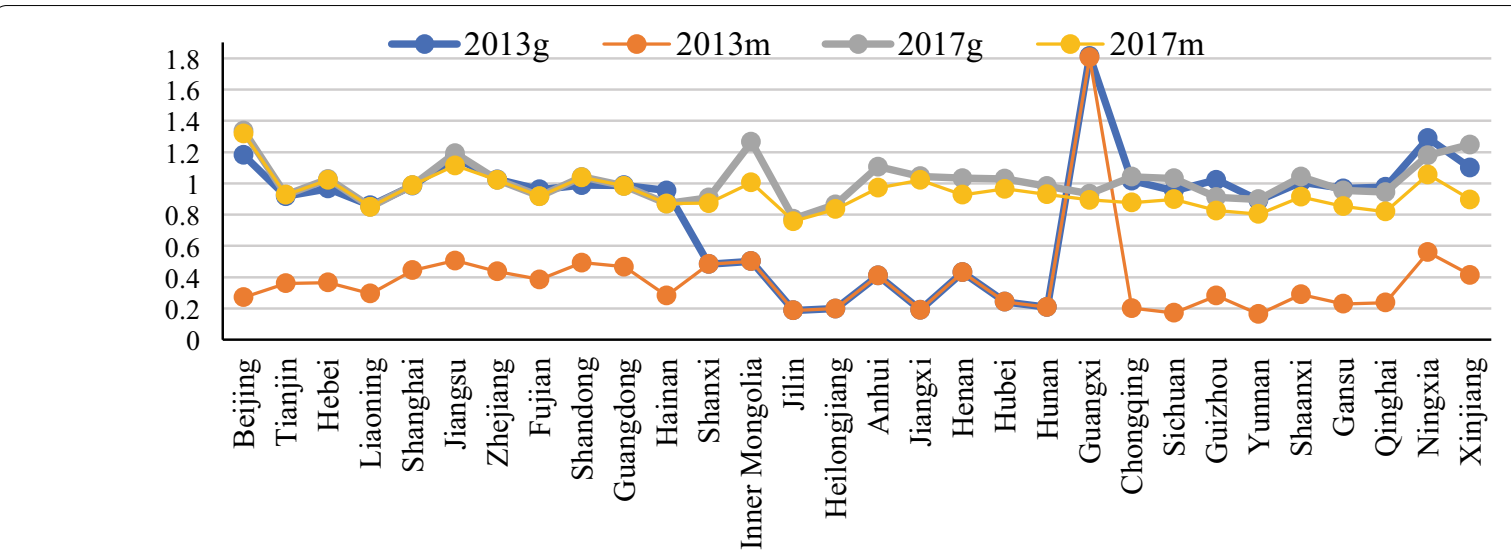

Fig. 3 China's provincial group efficiency and meta-efficiency scores of thermal power in 2013 and 2017. The data are from the authors' collection

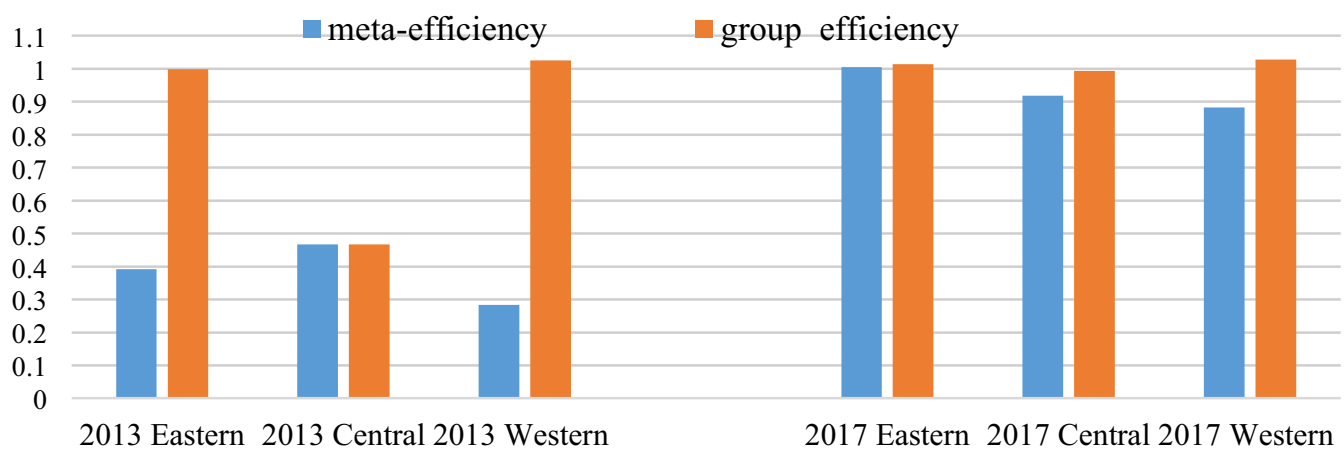

Fig. 4 China's eastern, central, and western regional group efficiency and meta-efficiency scores of thermal power in 2013 and 2017. The data are from the authors' collection

that used the meta-Frontier method to measure environmental efficiency or eco-efficiency, such as Mei et al. [19] and Beltrán-Esteve et al. [33].

In 2013, the average thermal power generation group efficiency score of the three regions was 0.9992, 0.4674, and 1.0253. By comparison, in 2017, the average thermal power generation group efficiency score was 1.0143, 0.9939 , and 1.0279. The average group efficiency of the central region has greatly improved, and the eastern and western regions are also on the rise. More importantly, comparing the meta- and group efficiency scores of the three regions, we see that the gap between the two efficiency scores of thermal power in the eastern and western regions has significantly narrowed, indicating that the production technology is getting closer and closer to the potential technology level. These results show that the development of the thermal power generation industry in the eastern, central, and western regions is gradually becoming mature and stable.

Figure 5 shows the comparison between the group efficiency score and the meta-efficiency score of hydropower generation in China's provinces in 2013 and 2017. In terms of hydropower generation, in the eastern region, the group efficiency scores of Zhejiang, Fujian, and Hainan are greater than 1, and in the western region, the group efficiency scores of Sichuan, Yunnan, Shaanxi, and Gansu are also greater than 1 . In the central region, only Hubei's group efficiency scores is greater than 1 .

Figure 6 shows the comparison results of the group efficiency and meta-efficiency of hydropower generation in the eastern, central, and western regions of China in 2013 and 2017. Among them, the average hydropower generation group efficiency score of the three regions in 2013 was $1.2759,1.1135$, and 1.1614. In 2017, the average hydropower generation group efficiency scores of the three regions was 1.2026, 1.0269, and 1.0956, and the average group efficiency scores of the three major regions showed a slight downward trend. Furthermore, comparing the meta- and group efficiency scores of the three regions, we see that the gap between the two efficiency scores of hydropower in Eastern and Central China has significantly widened, indicating that the gap between 


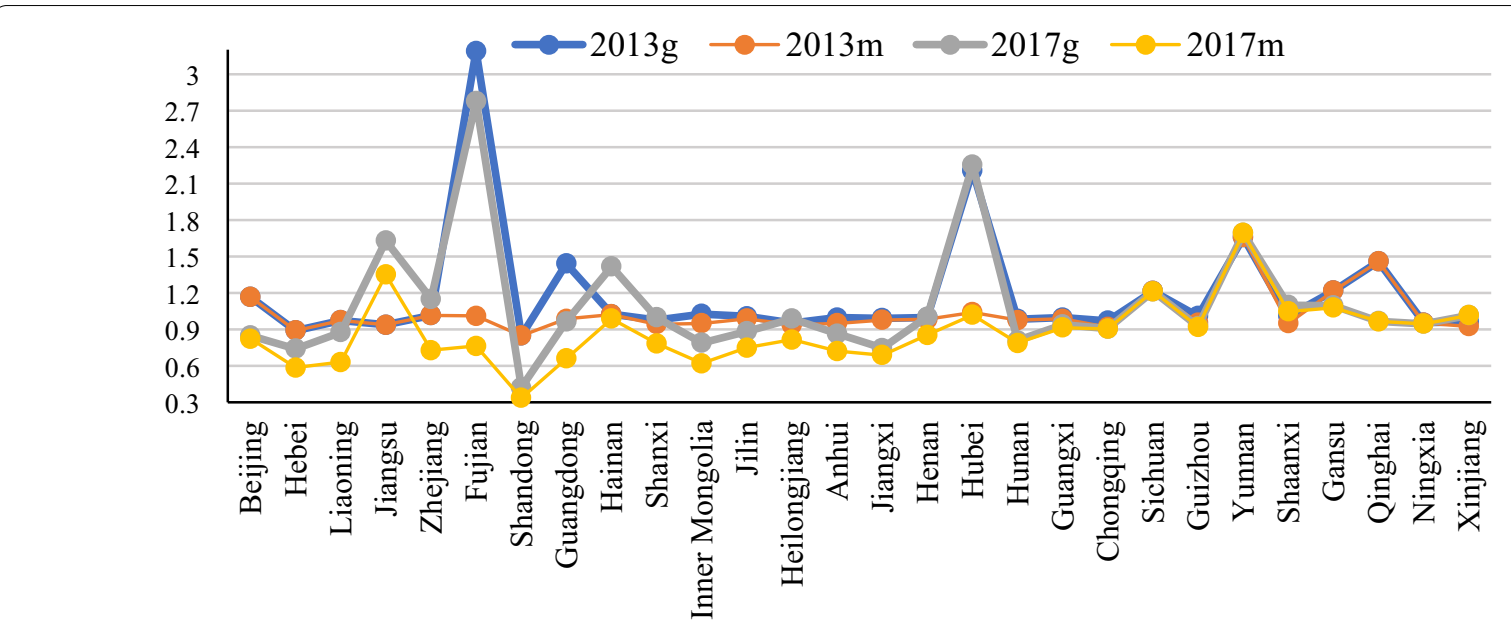

Fig. 5 China's provincial group efficiency and meta-efficiency scores of hydropower in 2013 and 2017. The data are from the authors' collection

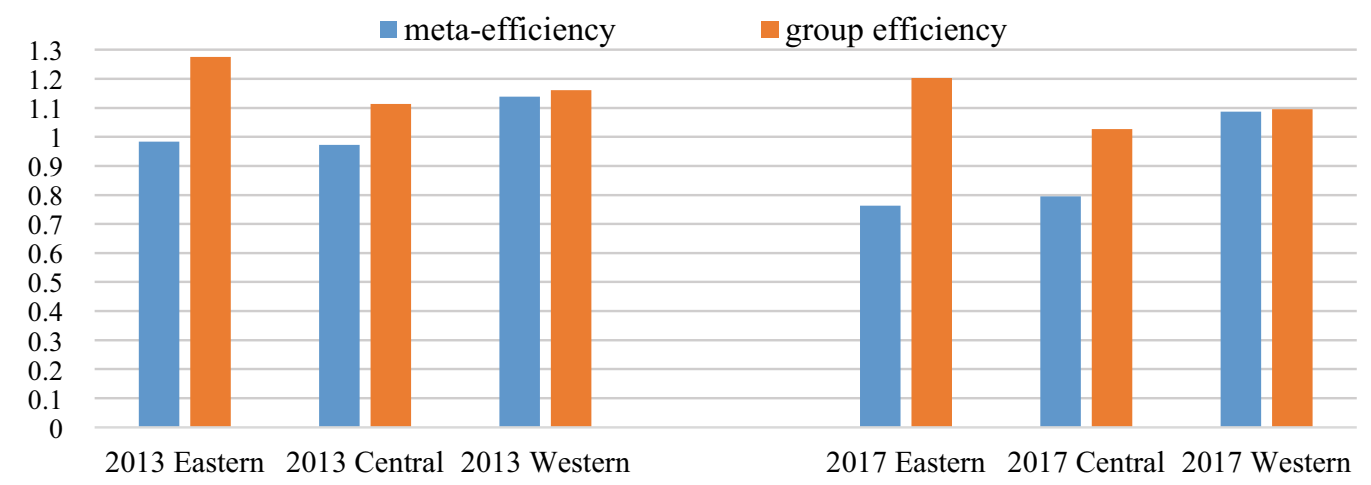

Fig. 6 China's eastern, central, and western regional group efficiency and meta-efficiency scores of hydropower in 2013 and 2017 . The data are from the authors' collection

the technology level and the level of potential production technology has widened. The hydropower generation technology in the three regions needs to be further improved, and the development of the hydropower generation industry needs continuous encouragement and promotion.

\section{Technology gap ratio (TGR) scores and rankings of thermal power and hydropower}

Table 6 lists the TGR rankings and TGR values of the efficiency of thermal power and hydropower generation in the meta- and group boundaries of China's provinces in 2013 and 2017. The specific analysis is as follows.

In 2017, there were five provinces in the eastern region tied for first place with a TGR of 1: Tianjin, Liaoning, Shanghai, Fujian, and Guangdong. Compared to 2013, the TGR rankings of the provinces in the central region in 2017 decreased significantly. Inner Mongolia, Anhui, and Henan dropped by 28, 23, and 19 places, respectively. In contrast, in the western region, Yunnan rose by 7 places, indicating that its thermal power industry's $\mathrm{CO}_{2}$ emissions have improved, while the remaining western provinces have relatively stable ranking changes.

In 2017, the thermal power efficiency TGR values of the eastern provinces were better than those of the central and western provinces. The socioeconomic development, industrialization and urbanization levels and the regional industry management level of the eastern region were superior to those of the central and western regions, which made the thermal power generation technology level in the eastern region better.

Figure 7 shows the TGR values of the thermal power generation efficiency of the eastern, central, and western regions in 2013 and 2017. In 2017, the TGR values of the thermal power generation efficiency of the eastern and western regions showed a rising trend, while those 
Table 6 Technology gap ratio (TGR) and rankings of thermal power and hydropower in 2013 and 2017

\begin{tabular}{|c|c|c|c|c|c|c|c|c|}
\hline \multirow[t]{3}{*}{ DMU } & \multicolumn{4}{|c|}{ Thermal power } & \multicolumn{4}{|c|}{ Hydropower } \\
\hline & \multicolumn{2}{|l|}{2013} & \multicolumn{2}{|l|}{2017} & \multicolumn{2}{|l|}{2013} & \multicolumn{2}{|l|}{2017} \\
\hline & Rank & TGR & Rank & TGR & Rank & TGR & Rank & TGR \\
\hline Beijing & 27 & 0.2300 & 10 & 0.9868 & 1 & 1 & 11 & 0.9693 \\
\hline Tianjin & 18 & 0.3924 & 1 & 1 & - & - & - & - \\
\hline Hebei & 19 & 0.3785 & 9 & 0.9953 & 1 & 1 & 20 & 0.7903 \\
\hline Liaoning & 21 & 0.3434 & 1 & 1 & 1 & 1 & 23 & 0.7206 \\
\hline Shanghai & 13 & 0.4513 & 1 & 1 & - & - & - & - \\
\hline Jiangsu & 15 & 0.4346 & 18 & 0.9346 & 1 & 1 & 17 & 0.8294 \\
\hline Zhejiang & 16 & 0.4256 & 7 & 0.9988 & 1 & 1 & 26 & 0.6332 \\
\hline Fujian & 17 & 0.4012 & 1 & 1 & 28 & 0.3171 & 28 & 0.2749 \\
\hline Shandong & 11 & 0.4984 & 8 & 0.9975 & 1 & 1 & 19 & 0.7970 \\
\hline Guangdong & 12 & 0.4732 & 1 & 1 & 26 & 0.6851 & 25 & 0.6834 \\
\hline Hainan & 22 & 0.2960 & 6 & 0.9999 & 1 & 1 & 24 & 0.6968 \\
\hline Eastern mean & 2 & 0.3931 & 1 & 0.9921 & 3 & 0.8891 & 3 & 0.7105 \\
\hline Shanxi & 1 & 1 & 14 & 0.9621 & 19 & 0.9639 & 22 & 0.7844 \\
\hline Inner Mongolia & 1 & 1 & 29 & 0.7951 & 25 & 0.9248 & 21 & 0.7852 \\
\hline Jilin & 1 & 1 & 11 & 0.9807 & 18 & 0.9809 & 15 & 0.8479 \\
\hline Heilongjiang & 1 & 1 & 13 & 0.9644 & 17 & 0.9819 & 18 & 0.8262 \\
\hline Anhui & 1 & 1 & 24 & 0.8787 & 21 & 0.9529 & 16 & 0.8346 \\
\hline Jiangxi & 1 & 1 & 12 & 0.9784 & 15 & 0.9859 & 13 & 0.9210 \\
\hline Henan & 1 & 1 & 20 & 0.8973 & 16 & 0.9858 & 14 & 0.8505 \\
\hline Hubei & 1 & 1 & 17 & 0.9386 & 27 & 0.4717 & 27 & 0.4521 \\
\hline Hunan & 1 & 1 & 16 & 0.9472 & 13 & 0.9908 & 9 & 0.9752 \\
\hline Guangxi & 10 & 0.9951 & 15 & 0.9586 & 14 & 0.9904 & 10 & 0.9732 \\
\hline Central mean & 1 & 0.9995 & 2 & 0.9301 & 2 & 0.9229 & 2 & 0.8250 \\
\hline Chongqing & 28 & 0.1988 & 28 & 0.8415 & 23 & 0.9458 & 6 & 0.9969 \\
\hline Sichuan & 30 & 0.1805 & 26 & 0.8702 & 1 & 1 & 1 & 1 \\
\hline Guizhou & 24 & 0.2760 & 19 & 0.9073 & 22 & 0.9478 & 7 & 0.9934 \\
\hline Yunnan & 29 & 0.1834 & 22 & 0.8953 & 1 & 1 & 1 & 1 \\
\hline Shaanxi & 23 & 0.2871 & 25 & 0.8775 & 24 & 0.9405 & 12 & 0.9525 \\
\hline Gansu & 26 & 0.2371 & 23 & 0.8943 & 1 & 1 & 8 & 0.9836 \\
\hline Qinghai & 25 & 0.2432 & 27 & 0.8678 & 1 & 1 & 5 & 0.9971 \\
\hline Ningxia & 14 & 0.4346 & 21 & 0.8963 & 12 & 0.9982 & 1 & 1 \\
\hline Xinjiang & 20 & 0.3764 & 30 & 0.7187 & 20 & 0.9616 & 1 & 1 \\
\hline Western mean & 3 & 0.2686 & 3 & 0.8632 & 1 & 0.9771 & 1 & 0.9915 \\
\hline
\end{tabular}

in the central region declined. The development trends of the TGR of the thermal power generation efficiency of the three major regions are not consistent. However, the gap in thermal power technology in the eastern, central, and western regions has gradually narrowed, indicating that the technology gap in thermal power generation efficiency between the group Frontier and meta-Frontier is $\mathrm{dwindling}$. This result is similar to the findings of Kumar and Jain [60], who analyzed the technology gaps in the thermal power industry in India based on the metaFrontier method. Our results show that technology in the thermal power industry is becoming more mature and that $\mathrm{CO}_{2}$ emissions control and treatment have made some progress.

To analyze the characteristics of and differences in hydropower TGR in the three regions, we perform $K$-means clustering on the TGR values of China's eastern, central, and western regions in 2017. Here, $K$ is set to 2 and is divided into two categories: a group with higher TGR values and a group with lower TGR values. The clustering results are presented in Table 7 .

Tables 6 and 7 clearly show that the hydropower efficiency TGR values of the western provinces in 2017 were significantly better than those of the eastern and central 


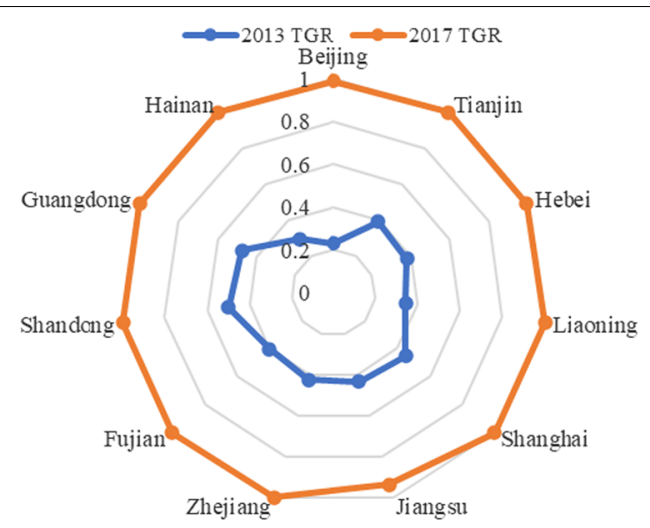

(a)

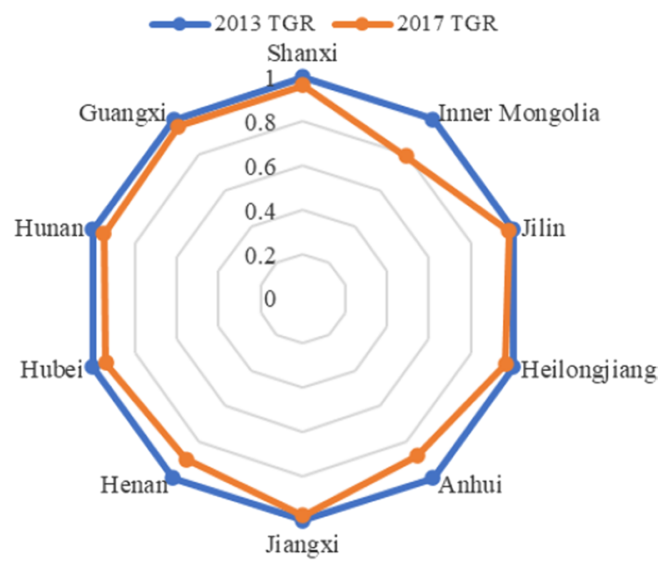

(b)

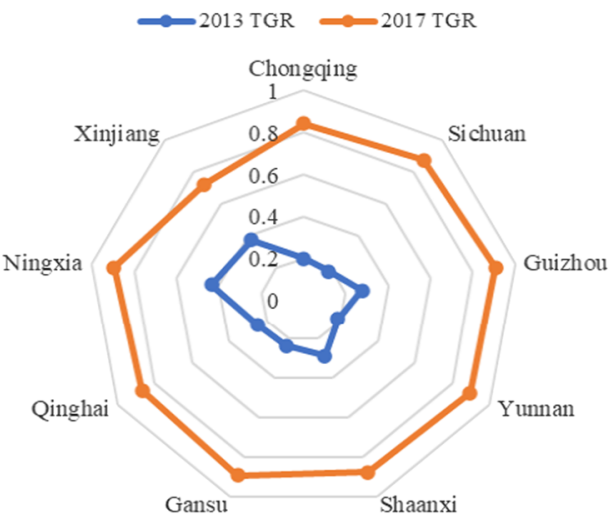

(c)

Fig. 7 a TGR of thermal power in Eastern China, b TGR of thermal power in Central China, and c TGR of thermal power in Western China in 2013 and 2017. The data are from the authors' collection

regions. In 2017, four provinces in the western region tied for first place with a TGR of 1: Sichuan, Yunnan, Ningxia, and Xinjiang. Moreover, the rankings of provinces in the western region have risen. In 2017, Xinjiang and Chongqing increased their rankings by 19 and 17 places, respectively, indicating that their hydropower industry development has been greatly promoted and that the technology level of their hydropower industry has greatly improved. However, compared to 2013, the TGR values and rankings of the eastern provinces in 2017 decreased significantly, indicating that policy support for and the stability of hydropower development in the eastern region need to be strengthened. Thus, efforts must be made to improve their hydropower generation technology.
Figure 8 shows the TGR values of hydropower energy efficiency in the eastern, central, and western regions for 2013 and 2017. The TGR values in the western region continued to increase, while those in the central and eastern regions declined. The development trends of the TGR for the hydropower energy efficiency in the three major regions are not consistent. Moreover, the technology gap among the western, central, and eastern regions has slightly expanded. The reason for this expansion may be related to the decentralization of approval authority for thermal power projects, leading to barriers between provinces to a certain extent and affecting the optimal allocation of resources [60]. Considering construction cost savings and profit maximization and due to inadequate environmental supervision, more thermal power 
Table 7 Provincial K-means clustering results for the technology gap ratio (TGR) of hydropower in China's three regions

\begin{tabular}{|c|c|}
\hline DMU & $\begin{array}{l}\text { K-means } \\
\text { clustering }\end{array}$ \\
\hline \multicolumn{2}{|l|}{ Eastern region } \\
\hline Beijing & 1 \\
\hline Hebei & 1 \\
\hline Liaoning & 1 \\
\hline Jiangsu & 1 \\
\hline Zhejiang & 2 \\
\hline Fujian & 2 \\
\hline Shandong & 1 \\
\hline Guangdong & 1 \\
\hline Hainan & 1 \\
\hline \multicolumn{2}{|l|}{ Central region } \\
\hline Shanxi & 1 \\
\hline Inner Mongolia & 1 \\
\hline Jilin & 1 \\
\hline Heilongjiang & 1 \\
\hline Anhui & 1 \\
\hline Jiangxi & 1 \\
\hline Henan & 1 \\
\hline Hubei & 2 \\
\hline Hunan & 1 \\
\hline Guangxi & 1 \\
\hline \multicolumn{2}{|l|}{ Western region } \\
\hline Chongqing & 1 \\
\hline Sichuan & 1 \\
\hline Guizhou & 1 \\
\hline Yunnan & 1 \\
\hline Shaanxi & 1 \\
\hline Gansu & 1 \\
\hline Qinghai & 1 \\
\hline Ningxia & 1 \\
\hline Xinjiang & 1 \\
\hline
\end{tabular}

"1" means the group with higher TGR values, and "2" means the group with lower TGR values. The data are from the authors' collection

plants are being built locally rather than accepting more renewable energy, such as hydropower, especially in the eastern and central regions. This situation has a negative impact on improving local hydropower generation.

\section{Improvement analysis of the input-output indicators of thermal power and hydropower}

Table 8 shows the input-output nonefficiency levels of thermal power generation in China's provinces in 2017 and the average input-output nonefficiency levels of thermal power generation in its three major regions. From the perspective of each group, the redundancy of the labor output in each region is relatively high [55], reaching more than $20 \%$, and there is a surplus of undesirable output $\mathrm{CO}_{2}$, i.e., $8 \%, 11 \%$, and $20 \%$ in the eastern, central, and western regions, respectively.

The equipment utilization hours, energy input, and installed capacity of the western region are especially high, and there is a shortage of thermal power generation output there. In addition, there is a large excess of undesirable output $\mathrm{CO}_{2}$, which means that there is a large amount of $\mathrm{CO}_{2}$ emissions, resulting in a relatively low efficiency of thermal power generation in Western China. Excessive resource input has not only failed to increase the expected output power generation but also greatly increased the undesired output of gas pollution emissions [55]. This finding shows that there is a lack of effective technical management and that more input does not mean more output, which leads to not only a waste of resources but also higher pollution control costs.

In the eastern region, there is much redundancy in the number of employees and energy input in Liaoning, and there is a large excess of undesirable output $\mathrm{CO}_{2}$, which places this province's thermal power energy efficiency last in the group. In the central region, Jilin also has a large amount of redundant inputs, and its input redundancy in regard to the number of employees and energy is $34 \%$ and $28 \%$, respectively. There is a large excess of undesirable output $\mathrm{CO}_{2}$, and its desirable output is insufficient. This situation puts Jilin's thermal power efficiency at the bottom of its group. In the western region, Yunnan has a severe surplus of employees and installed capacity, with redundancies of $68 \%$ and $47 \%$, respectively. Moreover, there is a serious shortage in thermal power generation output, placing its thermal power generation efficiency at the bottom of its group.

Table 9 shows the input-output nonefficiency levels of hydropower in China's provinces in 2017 and the average input-output nonefficiency levels of hydropower in its three major regions. From the perspective of each group, the labor force in the three major regions also has redundancy problems, reaching more than $20 \%$ in all three regions. In Eastern China, the equipment utilization hours, number of employees, and installed capacity are severely redundant, and the output of hydropower generation in the eastern and central regions is insufficient, reaching $49 \%$ and $28 \%$, respectively. These insufficiencies are also the reasons for the relatively low hydropower efficiency in the eastern and central regions.

In the eastern region, Shandong has a large number of employees, with a redundancy of $80 \%$, and the desirable output of hydropower generation is insufficient, reaching $197 \%$, which is the reason Shandong's hydropower energy efficiency is at the bottom of the group. In the central region, Inner Mongolia also has a large amount of redundancy. The redundancy in the number of employees and 


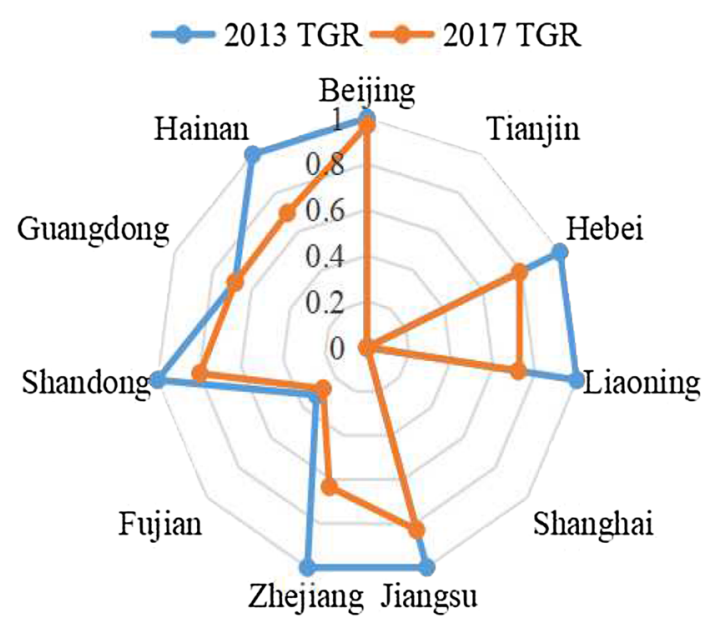

(a)

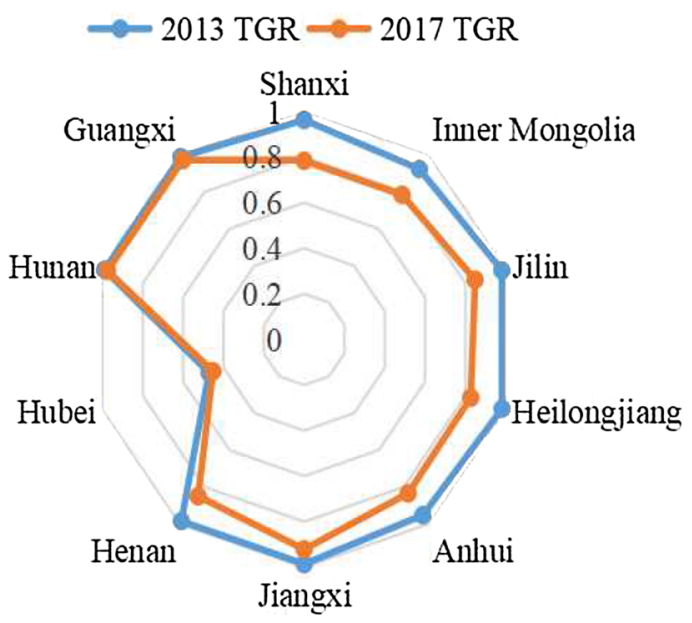

(b)

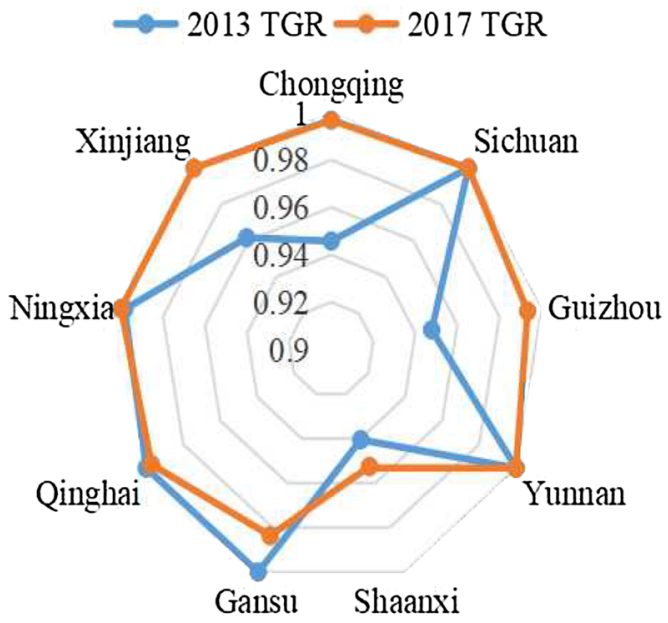

(c)

Fig. 8 a TGR of hydropower in Eastern China; b TGR of hydropower in Central China, and c TGR of hydropower in Western China in 2013 and 2017. The data are from the authors' collection

installed capacity reaches $34 \%$ and $18 \%$, respectively, and the desirable output of hydropower generation is insufficient, i.e., $61 \%$. As a result, Inner Mongolia's hydropower energy efficiency is at the bottom of the group.

\section{Discussion}

Comparing our results with those of previous studies, we see that there are some similarities and differences herein.

First, we observe that the average meta-efficiency scores of thermal power generation in China's three regions all show an upward trend, which is consistent with the findings of Zhou et al. [54]. However, Zhou et al. [54] measured the overall efficiency of China's thermal power industry based only on traditional DEA models that use emissions as an input variable.

Second, Wang et al. [24] found that the coal intensity of power plants in Eastern China is lower than that in the other regions. Chen and Zhu [61] found that the environmental efficiency of the thermal power industry in Eastern China ranks first and that Central China has the lowest environmental efficiency. Our results show that thermal power generation efficiency is higher in the eastern region and lower in the central and western regions, which is consistent with the findings of Wang et al. [24] and Chen and Zhu [61]. However, Wang et al. [24] discussed the microlevel of thermal power plants and did not consider $\mathrm{CO}_{2}$ emissions; thus, macroregional analysis considering $\mathrm{CO}_{2}$ emissions is needed. Chen and $\mathrm{Zhu}$ [61] 
Table 8 Analysis of the nonefficiency level of the input-output items of thermal power in 2017 (\%)

\begin{tabular}{|c|c|c|c|c|c|c|}
\hline $\mathrm{DMU}$ & Hours & Labor & Energy & Installed capacity & Generation capacity & $\mathrm{CO}_{2}$ \\
\hline Beijing & -83 & -69 & -34 & -53 & -48 & 0 \\
\hline Tianjin & -57 & 0 & -15 & 0 & 0 & -16 \\
\hline Hebei & 0 & -45 & -5 & 0 & -4 & 0 \\
\hline Liaoning & 0 & -27 & -24 & 0 & 5 & -30 \\
\hline Shanghai & -62 & 0 & -4 & -10 & 0 & -2 \\
\hline Jiangsu & 0 & 0 & -3 & -15 & -21 & 0 \\
\hline Zhejiang & 0 & 0 & 0 & -14 & -4 & 0 \\
\hline Fujian & -13 & 0 & -6 & 0 & 10 & -8 \\
\hline Shandong & 0 & -45 & 0 & -12 & -7 & 0 \\
\hline Guangdong & 0 & -59 & -3 & -10 & 0 & -3 \\
\hline Hainan & -77 & 0 & -21 & 0 & 0 & -30 \\
\hline Eastern mean & -27 & -22 & -10 & -10 & -6 & -8 \\
\hline Shanxi & -6 & 0 & -7 & 0 & 19 & -10 \\
\hline Inner Mongolia & 0 & 0 & -32 & -4 & -1 & 0 \\
\hline Jilin & 0 & -34 & -28 & 0 & 28 & -36 \\
\hline Heilongjiang & 0 & -47 & -15 & 0 & 16 & -24 \\
\hline Anhui & -19 & 0 & -2 & 0 & 0 & -6 \\
\hline Jiangxi & -47 & -4 & 0 & 0 & -4 & 0 \\
\hline Henan & 0 & -55 & 0 & -2 & 13 & -3 \\
\hline Hubei & 0 & -39 & -1 & -3 & 0 & -7 \\
\hline Hunan & 0 & -47 & -6 & -12 & 0 & -15 \\
\hline Guangxi & 0 & -46 & 0 & -25 & 15 & -8 \\
\hline Central mean & -7 & -27 & -9 & -5 & 9 & -11 \\
\hline Chongqing & -5 & 0 & -17 & -21 & 0 & -28 \\
\hline Sichuan & 0 & -78 & -12 & -44 & 0 & -23 \\
\hline Guizhou & -5 & 0 & -19 & 0 & 18 & -24 \\
\hline Yunnan & 0 & -68 & 0 & -47 & 40 & -9 \\
\hline Shaanxi & 0 & 0 & -13 & 0 & 0 & -19 \\
\hline Gansu & 0 & -34 & -11 & 0 & 15 & -19 \\
\hline Qinghai & -75 & 0 & -28 & 0 & 3 & -41 \\
\hline Ningxia & -77 & 0 & -28 & -16 & -11 & 0 \\
\hline Xinjiang & -24 & 0 & -15 & 0 & 4 & -19 \\
\hline Western mean & -21 & -20 & -16 & -14 & 8 & -20 \\
\hline
\end{tabular}

adopted the SBM-undesirable model but did not consider regional heterogeneity.

Third, China's hydropower industry has been developed, especially in areas rich in hydropower resources. Nonetheless, the efficiency of the country's hydropower industry needs to be improved, which is similar to the findings of Liu et al. [5] and Chang et al. [26]. However, Liu et al. [5] analyzed only the hydropower resources of Yunnan in China, while Chang et al. [26] analyzed only the Longyangxia station on the Yellow River. That is, they examined the efficiency of hydropower plants only in a certain province or region in China; thus, a more comprehensive regional survey of the country's hydropower industry is lacking.
China's hydropower and thermal power constitute the two pillars of its electricity supply and have a great impact on the green development of the power industry. Given the important role of hydropower in China but the limited attention paid to its regional efficiency evaluation, our assessment of the efficiency of China's regional hydropower generation aims to fill the research gap on this subject to a certain extent. Therefore, the efficiency values, TGR values and input-output nonefficiency levels of regional thermal power and hydropower generation in China are calculated and analyzed based on the meta-SE-SBM undesirable model, which can provide a more accurate efficiency evaluation of and development status reference on traditional energy 
Table 9 Analysis of the nonefficiency level of the input-output items of hydropower in 2017 (\%)

\begin{tabular}{lrrrrc}
\hline DMU & Hours & Labor & Energy & $\begin{array}{c}\text { Installed } \\
\text { capacity }\end{array}$ & $\begin{array}{c}\text { Generation } \\
\text { capacity }\end{array}$ \\
\hline Beijing & -52 & -42 & 0 & 0 & 22 \\
Hebei & 0 & -53 & 0 & 0 & 71 \\
Liaoning & 0 & -17 & 0 & 0 & 58 \\
Jiangsu & -45 & -80 & 0 & -72 & -26 \\
Zhejiang & 0 & -53 & 0 & -40 & 37 \\
Fujian & -22 & 0 & -19 & 0 & 31 \\
Shandong & 0 & -80 & 0 & 0 & 197 \\
Guangdong & 0 & -69 & 0 & -26 & 52 \\
Hainan & -78 & 0 & 0 & -29 & 1 \\
Eastern mean & -22 & -44 & -2 & -19 & 49 \\
Shanxi & 0 & -16 & 0 & 0 & 28 \\
Inner Mongolia & 0 & -34 & 0 & -18 & 61 \\
Jilin & 0 & 0 & 0 & 0 & 34 \\
Heilongjiang & -61 & -77 & 0 & 0 & 23 \\
Anhui & 0 & 0 & 0 & -1 & 39 \\
Jiangxi & 0 & -23 & 0 & -13 & 46 \\
Henan & 0 & -48 & 0 & 0 & 17 \\
Hubei & 0 & -27 & 0 & -1 & -2 \\
Hunan & 0 & -31 & 0 & -3 & 27 \\
Guangxi & -6 & 0 & 0 & -3 & 9 \\
Centralmean & -7 & -26 & 0 & -4 & 28 \\
Chongqing & -44 & 0 & 0 & -9 & 11 \\
Sichuan & 0 & -51 & -19 & -15 & -17 \\
Guizhou & -25 & 0 & 0 & -8 & 9 \\
Yunnan & -51 & 0 & -40 & -43 & -41 \\
Shaanxi & -46 & -25 & 0 & 0 & -5 \\
Gansu & -61 & -59 & 0 & 0 & -7 \\
Qinghai & -74 & 0 & 0 & -28 & 4 \\
Ningxia & -93 & -74 & 0 & 0 & 6 \\
Xinjiang & -17 & 0 & 0 & -14 & -2 \\
Western mean & -46 & -23 & -7 & -13 & -5 \\
\hline & & & & & \\
\hline
\end{tabular}

and renewable energy for government officials and power industry managers. Our results show that the gap in thermal power technology in the eastern, central, and western regions of China has narrowed, while the technology gap in hydropower in the three regions has expanded.

We suggest that future research should take the following directions. On the one hand, this study has some limitations in grouping China's various provinces based on the geographical attributes of three groups, i.e., Eastern, Central, and Western China. The grouping method for other economic attributes also needs to be further explored to determine whether they may have any significant influence on efficiency. On the other hand, this study compares the efficiency of thermal power and hydropower generation in China's three regions. With the development of renewable energy and data availability, the efficiencies of more types of electricity, such as wind power and solar power, can be compared.

\section{Conclusions and policy recommendations Conclusion}

1. There exist regional differences in hydropower generation efficiency and thermal power generation efficiency in China's eastern, central, and western regions. The eastern region has the highest thermal power efficiency, while the western region has the highest hydropower efficiency. This result mainly relates to the economic development level of the regions and their own resource endowments. The better economic foundation and good management of the eastern region allow its regional thermal power efficiency to be relatively high. With relatively rich hydropower resources, the western region also has a relatively high regional hydropower energy efficiency.

2. The trends of thermal power and hydropower TGR values in the three major regions of China are inconsistent, indicating that in these regions, the technological convergence of neither hydropower nor thermal power has been achieved. In 2017, the thermal power TGR values of the eastern region were better than those of the central and western regions; moreover, the thermal power TGR values of the central provinces dropped significantly. While the hydropower TGR values of the western region were better than those of the eastern and central regions, those of the eastern provinces dropped significantly.

3. The gap in thermal power technology among the three regions has gradually narrowed; conversely, the gap in hydropower technology among the three regions has slightly expanded. This result indicates that the technology in the thermal power industry is maturing and that $\mathrm{CO}_{2}$ emissions control and treatment have made progress. However, policy support for hydropower development is not sufficiently stable. With China's thermal power in a dominant position, the development of the hydropower industry needs government support to increase the proportion of renewable energy.

4. The input-output nonefficiency level results for thermal power and hydropower generation provide a reference for improving regional power generation efficiency. The undesirable output of $\mathrm{CO}_{2}$ in the central and western regions is excessive, reaching $11 \%$ and $20 \%$, respectively. Furthermore, the desirable 
output of hydropower generation in the eastern and central regions is insufficient, reaching $49 \%$ and $28 \%$, respectively. To improve China's thermal power generation efficiency, it is necessary not only to improve the operational level and benefits by reducing equipment utilization hours, installed capacity, and energy but also to reduce $\mathrm{CO}_{2}$ emissions, especially in Western China. It is also important to enhance China's hydropower generation efficiency by increasing local government support and technological innovation to increase the generation of hydropower, especially in Eastern China.

\section{Policy recommendations}

Considering the efficiency values, technology gaps, and input-output nonefficiency levels of thermal power and hydropower generation in China's provinces, policy suggestions for meeting the actual conditions are offered to help the green development of China's power industry.

First, considering the dominant position of thermal power in China's power industry and regional heterogeneity, local governments should enhance the efficiency of thermal power, promote the diversification of the energy structure in an orderly manner, and reasonably adjust the scale and structure of the power industry. Improving the efficiency of thermal power is important for achieving the green development of the whole power industry and environmental protection. Inefficient provinces-for example, the eastern provinces of Liaoning and Hainan, the central provinces of Jilin and Heilongjiang, and the western provinces of Guizhou, Yunnan, and Qinghaineed to improve their thermal power generation efficiencies based on their own situation, including enhancing research and development ( $R \& D)$ investment to reduce the technology gap, promoting technological innovation, adopting energy-saving production equipment, optimizing the pollution discharge treatment of coal-fired power generation, and training thermal power industry employees.

Second, regional governments can formulate policies to encourage the development of the hydropower industry based on their own resource endowment, increase the status of renewable energy in the entire power industry, and subsequently reduce carbon dioxide emissions and environmental pollution from the production root. Policies can be enacted, such as implementing west-east energy transmission [62], breaking geographical restrictions on hydropower development, and sending more hydropower from Western China to Eastern China to promote the full use of Western China's advantages in abundant hydropower resources.
The eastern provinces of Guangdong, Hebei, Liaoning, and Shandong, the central provinces of Jiangxi and Inner Mongolia, and the western provinces of Guizhou and Chongqing need to encourage the development of renewable energy, such as hydropower, wind power, and solar power, in the local power industry through environmental subsidies and policy support. They can also strengthen environmental supervision to encourage more companies to enter the renewable energy industry to expand the scale and to strengthen the competitiveness of renewable energy in the power market.

Third, in addition to the important role played by the government in the development of the power industry, attention should be paid to the fundamental role of the market in the industry's resource allocation. China's central and local governments should continue to promote green and efficient power industry market reforms. Through the reform of the electricity price mechanism, local governments and power industry managers can eliminate outdated thermal power, reduce the phenomenon of excess capacity, and allocate resources efficiently. The efficiency improvement brought by technological progress must be reflected in electricity prices to achieve the optimal allocation of resources in the power generation industry. Finally, authorities can speed up the technological innovation and technology diffusion of the power industry through a combination of government management and market regulation that can help narrow the regional technology gaps in the thermal power and hydropower industries to realize the coordinated development of traditional energy and renewable energy, providing an energy guarantee for regional economic development.

\section{Acknowledgements}

All authors have read and agreed to the published version of the manuscript.

\section{Authors' contributions \\ Conceptualization, R-MW and F-RR; methodology, F-RR; software, ZT; valida- tion R-MW; formal analysis, R-MW; investigation, R-MW and F-FR; resources, $\mathrm{ZT}$; data curation, R-MW; writing —original draft preparation, R-MW; writing- review and editing, ZT; visualization, R-MW; supervision, R-MW, ZT and F-RR; project administration, F-RR; funding acquisition, F-RR. All authors read and approved the final manuscript.}

\section{Funding}

This study was supported by the Fundamental Research Funds for the Central Universities (B210203151, B200203170 and B200207043) and Postgraduate Research \& Practice Innovation Program of Jiangsu Province (KYCX20_0512).

\section{Availability of supporting data}

All data generated or analyzed during this study are included in this published article and its additional information files.

\section{Declarations}

Ethics approval and consent to participate

Not applicable. 


\section{Consent for publication}

Written informed consent for publication was obtained from all participants.

\section{Competing interests}

The authors declare no conflicts of interest.

\section{Author details}

'Business School, Hohai University, Focheng West Road No. 8, Nanjing 211100, China. ${ }^{2}$ Business School, Hohai University, Jinling North Road No. 200, Changzhou 213022, China.

Received: 27 October 2020 Accepted: 29 September 2021

Published online: 12 October 2021

\section{References}

1. BP (2020) BP Statistical Review of World Energy 2020. https://www.bp. com/content/dam/bp/business-sites/en/global/corporate/pdfs/energyeconomics/statistical-review/bp-stats-review-2020-full-report.pdf

2. Maleki A, Pourfayaz F, Hafeznia H, Rosen AM (2017) A novel framework for optimal photovoltaic size and location in remote areas using a hybrid method: a case study of eastern Iran. Energy Convers Manage 153:129-143

3. Vinel A, Mortaz E (2019) Optimal pooling of renewable energy sources with a risk-averse approach: implications for US energy portfolio. Energy Policy 132:928-939

4. Amoah A, Kwablah E, Korle K, Offei D (2020) Renewable energy consumption in Africa: the role of economic well-being and economic freedom. Energy Sustain Soc 10(1):32

5. Liu BX, Liao SL, Cheng CT, Chen F, Li WD (2018) Hydropower curtailment in Yunnan province, southwestern China: constraint analysis and suggestions. Renew Energy 121:700-711

6. China Electricity Council (2020) China electric power yearbook. China Electric Power Press, Beijing

7. Charnes A, Cooper WW, Rhodes E (1978) Measuring the efficiency of decision making units. Eur J Oper Res 2:429-444

8. Banker RD, Charnes A, Cooper WW (1984) Some models for estimating technical and scale inefficiencies in data envelopment analysis. Manage Sci 30(9):1078-1092

9. Chung YH, Färe R, Grosskopf S (1997) Productivity and undesirable outputs: a directional distance function approach. J Environ Manage 51(3):229-240

10. Tone K (2001) A slacks-based measure of efficiency in data envelopment analysis. Eur J Oper Res 130:498-509

11. Chang TP, Hu JL (2010) Total-factor energy productivity growth, technical progress, and efficiency change: an empirical study of China. Appl Energy 87(10):3262-3270

12. Yang ZS, Wei XX (2019) The measurement and influences of China's urban total factor energy efficiency under environmental pollution: based on the game cross-efficiency DEA. J Clean Prod 209:439-450

13. Shrivastava N, Sharma S, Chauhan K (2012) Efficiency assessment and benchmarking of thermal power plants in India. Energy Policy 40:159-176

14. Moon H, Min D (2017) Assessing energy efficiency and the related policy implications for energy-intensive firms in Korea: DEA approach. Energy 133:23-34

15. Choi Y, Zhang N, Zhou P (2012) Efficiency and abatement costs of energy-related $\mathrm{CO}_{2}$ emissions in China: a slacks-based efficiency measure. Appl Energy 98:198-208

16. Bi G, Song W, Zhou P, Liang L (2014) Does environmental regulation affect energy efficiency in China's thermal power generation? Empirical evidence from a slacks-based DEA model. Energy Policy 66:537-546

17. Song M, Wang J (2018) Environmental efficiency evaluation of thermal power generation in China based on a slack-based endogenous directional distance function model. Energy 161:325-336

18. Zhang N, Kong FB, Yu YN (2015) Measuring ecological total-factor energy efficiency incorporating regional heterogeneities in China. Ecol Ind 51:165-172
19. Mei GP, Gan JY, Zhang N (2015) Metafrontier environmental efficiency for China's regions: a slack-based efficiency measure. Sustainability 7:4004-4021

20. Eguchi S, Takayabu H, Lin C (2021) Sources of inefficient power generation by coal-fired thermal power plants in China: a metafrontier DEA decomposition approach. Renew Sustain Energy Rev 138:1 10562

21. Li H, Shi JF (2014) Energy efficiency analysis on Chinese industrial sectors: an improved Super-SBM model with undesirable outputs. J Clean Prod 65:97-107

22. Menéndez J, Fernández-Oro JM, Galdo M, Loredo J (2020) Efficiency analysis of underground pumped storage hydropower plants. J Energy Storage 28:101234

23. Xie J, Liang Z, Zhang XB, Zhu L (2019) Efficiency evaluation of thermal power plants in China based on the weighted Russell directional distance method. J Clean Prod 222:573-583

24. Wang CH, Cao XY, Mao J, Qin P (2019) The changes in coal intensity of electricity generation in Chinese coal-fired power plants. Energy Econ 80:491-501

25. Wu C, Oh K, Long XL, Zhang J (2019) Effect of installed capacity size on environmental efficiency across 528 thermal power stations in north China. Environ Sci Pollut Res 26:29822-29833

26. Chang JX, Li YY, Yuan M, Wang YM (2017) Efficiency evaluation of hydropower station operation: a case study of Longyangxia station in the Yellow River, China. Energy 135(15):23-31

27. Lima F, Nunes ML, Cunha J, Lucena A (2017) Driving forces for aggregate energy consumption: a cross-country approach. Renew Sustain Energy Rev 68:1033-1050

28. Liu X, Zhou D, Zhou P, Wang Q (2018) Factors driving energy consumption in China: a joint decomposition approach. J Clean Prod 172:724-734

29. Wang $\mathrm{H}$, Zhou P (2018) Assessing global $\mathrm{CO}_{2}$ emission inequality from consumption perspective: an index decomposition analysis. Ecol Econ 154:257-271

30. Meng M, Mander S, Zhao X, Niu D (2016) Have market-oriented reforms improved the electricity generation efficiency of China's thermal power industry? an empirical analysis. Energy 114:734-741

31. Li M, Song C, Tao W (2016) A hybrid model for explaining the short-term dynamics of energy efficiency of China's thermal power plants. Appl Energy 169:738-747

32. Perez K, González-Araya MC, Iriarte A (2017) Energy and GHG emission efficiency in the Chilean manufacturing industry: sectoral and regional analysis by DEA and Malmquist indexes. Energy Econ 66:290-302

33. Beltrán-Esteve M, Reig-Martínez E, Estruch-Guitart V (2017) Assessing ecoefficiency: a meta-frontier directional distance function approach using life cycle analysis. Environ Impact Assess Rev 63:116-127

34. Xue D, Yue L, Ahmad F, Umar Draz M, Ali Chandio A (2021) Urban ecoefficiency and its influencing factors in Western China: Fresh evidence from Chinese cities based on the US-SBM. Ecol Indic 127:107784

35. Wang ZH, Liu B, Wang LS, Shao Q (2021) Measurement and temporal \& spatial variation of urban eco-efficiency in the Yellow River Basin. Phys Chem Earth 122:102981

36. Ghosh R, Kathuria V (2016) The effect of regulatory governance on efficiency of thermal power generation in India: a stochastic frontier analysis. Energy Policy 89:11-24

37. Barros CP (2008) Efficiency analysis of hydroelectric generating plants: a case study for Portugal. Energy Econ 30:59-75

38. Barros CP, Wanke P, Dumbo S, Manso JP (2017) Efficiency in angolan hydro-electric power station: a two-stage virtual frontier dynamic DEA and simplex regression approach. Renew Sustain Energy Rev 78:588-596

39. Wang YP, Yan WL, Zhuang SW, Zhang Q (2019) Competition or complementarity? The hydropower and thermal power nexus in China. Renew Energy 138:531-541

40. Zhou DQ, Wu CS, Wang QW, Zha DL (2019) Response of scale and leverage of thermal power enterprises to renewable power enterprises in China. Appl Energy 251:113288

41. Yu D, He XR (2020) A bibliometric study for dea applied to energy efficiency: trends and future challenges. Appl Energy 268:115048

42. Ding XH, Zhang ZX, Wu FP, Xu XY (2019) Study on the evolution of water resource utilization efficiency in Tibet Autonomous Region and four provinces in Tibetan areas under double control action. Sustainability 11:3396 
43. O'Donnell CJ, Rao DSP, Battese GE (2008) Metafrontier frameworks for the study of firm-level efficiency and technology ratios. Empir Econ 34(2):231-255

44. Huang J (2016) Regional heterogeneity, ecological efficiency and green development. China Social Science Press, Beijing

45. Liu H, Zhang Y, Zhu Q, Chu J (2017) Environmental efficiency of land transportation in China: a parallel slack-based measure for regional and temporal analysis. J Clean Prod 142:867-876

46. National Bureau of Statistics of China (2018) China Statistical Yearbook. http://www.stats.gov.cn/

47. Department of Energy Statistical, National Bureau of Statistics of China (2018) China energy statistical yearbook. China Statistics Press, Beijing

48. China Electricity Council (2018) China electric power yearbook. China Electric Power Press, Beijing

49. Tian Z, Ren FR, Xiao QW, Chiu YH, Lin TY (2019) Cross-regional comparative study on carbon emission efficiency of China's Yangtze River economic belt based on the meta-Frontier. Int J Environ Res Public Health $16: 619$

50. Bai Y, Hua C, Jiao J, Yang M, Li F (2018) Green efficiency and environmental subsidy: evidence from thermal power firms in China. J Clean Prod 188:49-61

51. Zhou Y, Xing X, Fang K, Liang D, Xu C (2013) Environmental efficiency analysis of power industry in China based on an entropy SBM model. Energy Policy 57:68-75

52. Zhou $\mathrm{P}$, Ang $\mathrm{BW}$, Wang $\mathrm{H}$ (2012) Energy and $\mathrm{CO}_{2}$ emission performance in electricity generation: a non-radial directional distance function approach. Eur J Oper Res 221:625-635

53. Qin Q, Jiao Y, Gan X, Liu Y (2020) Environmental efficiency and market segmentation: an empirical analysis of China's thermal power industry. $J$ Clean Prod 242:118560

54. Zhou JG, Wang YX, Liang HT, Li B (2011) Total factor energy efficiency research on Chinese thermal power industry. East China Electr Power
39(6): 875-879. http://www.en.cnki.com.cn/Article_en/CJFDTOTALHDDL201106008.htm

55. Qu QQ, Xie BC, Yin KX (2012) Analysis of inter-provincial differences in efficiency of China's thermal power industry considering non-ideal output. Resour Sci 34(6):1160-1166

56. Saglam U (2017) A two-stage data envelopment analysis model for efficiency assessments of 39 state's wind power in the United States. Energy Convers Manage 146:52-67

57. Zhou P, Ang BW (2008) Linear programming models for measuring economy wide energy efficiency performance. Energy Policy 36:2911-2916

58. Liu Y, Zhao G, Zhao Y (2016) An analysis of Chinese provincial carbon dioxide emission efficiencies based on energy consumption structure. Energy Policy 96:524-533

59. Tian Z, Pan JJ, Ren FR (2020) DEA-based energy efficiency evaluation and improvement direction of inter-provincial hydropower in the Yangtze River Economic Belt. Water Resour Econ 38(4):1-7, 81

60. Kuma S, Jain RK (2019) Carbon-sensitive meta-productivity growth and technological gap: an empirical analysis of Indian thermal power sector. Energy Econ 81:104-116

61. Chen P, Zhu L (2016) Environmental efficiency measurement and influencing factors of China's thermal power industry. J Dongbei Univ Finan Econ 4:26-33

62. Ling ZL, Huang T, Li JX et al (2019) Sulfur dioxide pollution and energy justice in northwestern China embodied in west-east energy transmission of China. Appl Energy 238:547-560

\section{Publisher's Note}

Springer Nature remains neutral with regard to jurisdictional claims in published maps and institutional affiliations.
Ready to submit your research? Choose BMC and benefit from:

- fast, convenient online submission

- thorough peer review by experienced researchers in your field

- rapid publication on acceptance

- support for research data, including large and complex data types

- gold Open Access which fosters wider collaboration and increased citations

- maximum visibility for your research: over 100M website views per year

At BMC, research is always in progress.

Learn more biomedcentral.com/submissions 